\title{
Flavonoides das plantas do gênero Lavandula como potenciais inibidores de proteínas-chave do SARS-CoV-2
}

\author{
Flavonoids from plants of the Lavandula genus as potential inhibitors of key proteins of SARS-
} CoV-2

\section{Flavonoides de plantas del género Lavandula como inhibidores potenciales de proteínas clave del} SARS-CoV-2

\section{Resumo}

Objetivo: avaliar o perfil de interações entre os flavonoides frente às proteínas-chave da infecção pelo SARS-CoV-2, e de modo secundário, objetivou-se analisar as propriedades destes constituintes químicos frente à Regra de Lipinski como potenciais candidatos a fármacos. Metodologia: Este estudo caracteriza-se como do tipo quantitativo descritivo de caráter experimental, através de métodos computacionais, onde foram utilizados os programas AutoDock Tools, AutoDock Vina, Biovia Discovery Studio e ChimeraX para a realização do acoplamento molecular entre os principais flavonoides presentes nas plantas do gênero Lavandula com a proteína M e o complexo entre a Enzima Conversora de Angiotensina 2 e o domínio de ligação do receptor da proteína S do SARS-CoV-2. Resultados: Analisando-se as interações isoladas de cada flavonoide com as proteínas, nota-se que os compostos apresentaram interações mais favoráveis com a Enzima Conversora de Angiotensina 2 e o domínio de ligação do receptor. Para a regra de Lipinski, a Delfinidina apresentou duas violações, sendo considerada, neste contexto, uma molécula pouco promissora. Conclusão: Conclui-se, portanto, que os flavonoides apresentam in silico um potencial inibitório para as proteínas testadas, sendo mais favorável ao complexo da Enzima Conversora de Angiotensina 2 com o domínio de ligação ao receptor. Frente à regra de Lipinski, apenas a Delfinidina demonstrou baixo potencial para candidata a fármaco, contudo, o uso de nanocarreadores poderia contornar algumas de suas limitações.

Palavras-chave: SARS-CoV-2; Proteínas Flavonoides; In silico.

\begin{abstract}
Objective: to evaluate the profile of interactions between flavonoids against key proteins of SARS-CoV-2 infection, and secondarily, to analyze the properties of these chemical constituents against Lipinski's Rule as potential drug candidates. Methodology: This study is characterized as a quantitative descriptive experimental type, through computational methods, where AutoDock Tools, AutoDock Vina, Biovia Discovery Studio and ChimeraX were used to perform the molecular coupling between the main flavonoids present in plants from the Lavandula genus with the $\mathrm{M}$ protein and the complex between the Angiotensin-2 Converting Enzyme and the S protein receptor binding domain of SARS-CoV-2. Results: Analyzing the isolated interactions of each flavonoid with the proteins, it is noted that the compounds showed more favorable interactions with the Angiotensin 2 Converting Enzyme and the receptor binding domain. For Lipinski's rule, Delphinidin presented two violations, being considered, in this context, an unpromising molecule. Conclusion: It is concluded, therefore, that flavonoids in silico present an inhibitory potential for the tested proteins, being more favorable to the Angiotensin 2 Converting Enzyme complex with the receptor binding domain. In view of Lipinski's rule, only Delphinidin showed low potential as a drug candidate, however, the use of nanocarriers could circumvent some of its limitations.
\end{abstract}

Keywords: SARS-CoV-2; Proteins Flavonoids; In silico.

\section{Resumen}

Objetivo: evaluar el perfil de interacciones entre flavonoides frente a proteínas clave de la infección por SARS-CoV-2 $\mathrm{y}$, en segundo lugar, analizar las propiedades de estos constituyentes químicos frente a la regla de Lipinski como posibles fármacos candidatos. Metodología: Este estudio se caracteriza por ser de tipo experimental descriptivo cuantitativo, 
mediante métodos computacionales, donde se utilizaron AutoDock Tools, AutoDock Vina, Biovia Discovery Studio y ChimeraX para realizar el acoplamiento molecular entre los principales flavonoides presentes en plantas del género Lavandula con la M proteína y el complejo entre la enzima convertidora de angiotensina-2 y el dominio de unión al receptor de proteína S del SARS-CoV-2. Resultados: Al analizar las interacciones aisladas de cada flavonoide con las proteínas, se observa que los compuestos resultaron más favorables con la enzima convertidora de angiotensina 2 y el dominio de unión al receptor. Para la regla de Lipinski, la delfinidina presentó dos violaciones, considerándose, en este contexto, una molécula poco prometedora. Conclusión: Se concluye, por tanto, que los flavonoides in silico presentan un potencial inhibidor de las proteínas ensayadas, siendo más favorables al complejo de la enzima convertidora de angiotensina 2 con el dominio de unión al receptor. En vista de la regla de Lipinski, solo Delphinidin mostró un bajo potencial como candidato a fármaco, sin embargo, el uso de nanoportadores podría eludir algunas de sus limitaciones.

Palabras clave: SARS-CoV-2; Proteínas Flavonoides; In silico.

\section{Introdução}

Durante os anos 2002 e 2003 ocorreu à primeira Síndrome Respiratória Aguda-Grave, do inglês "Severe Acute Respiratoy Syndrome Coronavirus", a SARS-CoV, causadora da epidemia na China, originada de uma espécie de coronavírus. Em 2012, ocorreu a Middle East Respiratory Syndrome, também causada por uma espécie variante de coronavírus, que recebeu a nomenclatura de MERS-CoV. No final de 2019, a China relatou o surgimento de uma epidemia causada por uma nova variante do coronavírus, que foi chamada de SARS-CoV-2. Em 11 de março de 2020, a Organização Mundial da Saúde (OMS), elevou o estado de contaminação à pandemia de COVID-19 (abreviatura em inglês para Coronavirus Disease 19), nome dado à doença causada pelo novo coronavírus (Decaro \& Lorusso, 2020).

O SARS-CoV-2 trata-se de um microrganismo de formato esférico, com aproximadamente 125 nanômetros de diâmetro, com espículas que se projetam da superfície do vírus, o que confere ao mesmo a aparência de uma corona solar, de onde deriva o nome, coronavírus. Dentro envelope viral, encontram-se os nucleocapsídeos helicoidais simétricos, sendo raro entre vírus de ácido ribonucleico (RNA) de sentido positivo (Malik, 2020).

A via de entrada para o coronavírus no organismo humano é a respiratória, onde o microrganismo entra em contato com células específicas, os pneumócitos do tipo 2, os quais expressam uma importante enzima na superfície, a Enzima Conversora de Angiotensina 2 (ECA2), sendo essencial para que o vírus possa invadir as células do hospedeiro. A COVID-19 pode afetar os mais diversos sistemas além do respiratório, como o cardiovascular, renal, digestório e nervoso. Estudos apontam que a infecção se apresenta de forma heterogênea, afetando de forma diferente uma mesma população, onde nota-se que os indivíduos mais jovens e sem comorbidades comumente não desenvolvem os sintomas, ou quanto são sintomáticos, na maioria das vezes são sintomas leves. Por outro lado, pacientes idosos que quase sempre apresentam comorbidades como hipertensão, obesidade e diabetes são mais suscetíveis a desenvolverem o quadro grave da doença (Yuki, Fujiogi \& Koutsogiannaki, 2020).

Aos meados do século XXI, houve um grande aumento na descoberta de novas espécies animais e vegetais, bem como um grande avanço na área de estudo químico de produtos naturais. Atualmente, a maioria das opções terapêuticas disponíveis no mercado são obtidas de forma sintética, porém, a constante necessidade de novos fármacos ativos contra microrganismos emergentes, tais como vírus e bactérias, direcionou os esforços das pesquisas para a identificação de produtos naturais com propriedades bioativas, principalmente aqueles derivados de plantas (Viegas, Bolzani \& Barreiro, 2006;).

As plantas da família Lamiaceae apresentam uma distribuição cosmopolita, contando com aproximadamente 300 gêneros e 7.500 espécies, contando com 28 gêneros e cerca de 350 espécies presentes no Brasil. Nesta família, encontram-se as plantas do gênero Lavandula, conhecidas popularmente como lavandas ou alfazemas. O óleo essencial da lavanda tem sido amplamente utilizado nas mais diversas formas de terapia, seja em massagens devido às suas propriedades ansiolíticas e na aromaterapia, onde apresenta atividade em afecções do sistema respiratório, atuando como antitussígeno, podendo ainda ser utilizado nos estados de gripe, sinusite e bronquite, promovendo alívio dos sintomas. Possui ainda atividade antiespasmódica, 
sendo útil em problemas digestivos, além de ter sido demonstrada sua atividade antibacteriana e antifúngica (Silva, 2015; Ferreira, 2014).

$\mathrm{Na}$ literatura, encontram-se diversos estudos avaliando as propriedades antimicrobianas do óleo essencial de lavanda contra fungos e bactérias, contudo, há escassez de dados demonstrando sua atividade contra vírus. Um estudo conduzido pelo Departamento de Microbiologia, Centro de Pesquisa de Plantas Medicinais de Barijcom, na Itália, através do método de difusão em disco e microdiluição perante microrganismos gram-positivos e gram-negativos, apontou que as bactérias gram-positivas como Staphylococcus aureus e Bacillus cereus são mais suscetíveis do que as bactérias gram-negativas Escherichia coli e Salmonella typhimurium. A atividade antifúngica também foi relatada, onde as espécies Aspergillus niger e Candida albicans mostraram-se sensíveis nos testes, embora sejam necessárias grandes concentrações do óleo (Santos, Lima \& Moraes, 2019).

De acordo com Hamid, Aiyelaagbe e Usman (2011), as plantas produzem compostos metabólitos primários e secundários, os quais possuem inúmeras propriedades. Todos os seres vivos, animais ou vegetais, possuem um sistema de metabolismo geral comum denominado metabolismo primário, o qual tem por objetivo sintetizar compostos essenciais para que esses seres possam sobreviver. No metabolismo primário dos vegetais encontram-se associados os processos de fotossíntese que dão origem aos ácidos carboxílicos do ciclo de Krebs, os alfa-aminoácidos, hidrocarbonetos, ácidos graxos, proteínas e ácidos nucleicos, todos sendo vitais para as plantas. Através deste metabolismo, os processos químicos de cada planta ocorrem diariamente a fim de manter sua sobrevivência e garantir a reprodução (Almeida, 2017).

Os metabólitos secundários, por outro lado, originam-se do processo de conservação da energia luminosa em energia química, garantindo que a planta seja capaz de responder aos diferentes fatores do ambiente, sejam estes físicos ou biológicos, o que permite sua comunicação e interação com diversos organismos, seja atraindo ou repelindo, fornecendo sustentação ou destruindo-os. $\mathrm{O}$ uso de plantas para fins medicinais dá-se em virtude da extensa quantidade de metabólitos, principalmente secundários, produzidos pelas mesmas (Almeida, 2017; Gobbo-Neto \& Lopes, 2007).

Um ponto importante sobre os óleos essenciais diz respeito ao seu método de obtenção. Tais óleos podem ser extraídos por meio de diversas técnicas, sendo que suas propriedades dependerão do método extrativo. Cabe ainda ressaltar que a extração de óleos essenciais visa obter de forma majoritária os metabólitos secundários de uma planta, considerando que a maior parte de seus efeitos terapêuticos provem da via secundária de metabolismo, e caracterizam-se quimicamente como complexas misturas de compostos com baixo peso molecular, alguns com alta volatilidade, sendo capazes de produzir aromas e sabores. Dentre os processos mais utilizados, destacam-se: hidrodestilação, arraste a vapor, prensagem a frio, extração com solventes orgânicos, $\mathrm{CO}_{2}$ supercrítico e alta pressão (Machado \& Junior, 2011; Probst, 2012).

Os constituintes químicos extraídos de produtos da flora possuem diversas propriedades terapêuticas, como antiinflamatórias, antineoplásicas e antimicrobianas. A identificação destes compostos constitui-se como etapa fundamental para a elaboração de metodologias para a avaliação de suas possíveis propriedades terapêuticas e desenvolvimento de rotas de síntese. Diversas bases de dados hospedam as estruturas químicas dos compostos, como o PubChem, ChemSpider ou ZINC, de acesso gratuito, podendo obter as estruturas para realização de experimentos (Junior, Pinto \& Maciel, 2005; Sousa, et al., 2008).

Estudos computacionais constituem-se como uma metodologia rápida e eficiente no desenvolvimento de novos fármacos, onde através de estudos de acoplamento e dinâmica molecular, podem ser avaliadas as interações de micro e macromoléculas com diversos alvos terapêuticos. Um estudo in silico não substitui um estudo em seres vivos ou culturas celulares, mas este auxilia na predição da atividade de moléculas com potencial terapêutico. Filtros moleculares podem ser aplicados para delimitar características específicas de compostos, a fim de reduzir o número de testes, otimizando o tempo e contribuindo para menores custos no desenvolvimento. A exemplo pode-se citar a Regra de Lipinski, que estabelece parâmetros moleculares para definir se um determinado composto possui bom potencial para vir a ser um novo fármaco (Salum, 2007; 
Xavier, 2012). Desse modo, surgiu o seguinte questionamento: Os flavonoides em maiores concentrações nas plantas do gênero Lavandula podem atuar como potenciais inibidores das proteínas-chave na infecção pelo SARS-CoV-2?

Visando responder à problemática desta pesquisa, objetivou-se de modo primário avaliar o perfil de interações entre os flavonoides frente às proteínas-chave da infecção pelo SARS-CoV-2, e de modo secundário, objetivou-se analisar as propriedades destes constituintes químicos frente à Regra de Lipinski como potenciais candidatos a fármacos.

Tendo em vista a atual situação de pandemia e a falta de medicamentos com eficácia disponíveis, a necessidade por pesquisas visando o desenvolvimento de novos agentes terapêuticos faz-se necessária. Nos últimos meses, houve um crescente aumento no número de pesquisas envolvendo a procura por novos compostos com atividade antiviral capazes de impedir ou conter a infecção causada pelo novo coronavírus. Por tratar-se de uma planta relativamente comum em vários países pelo mundo, a Lavanda é amplamente utilizada popularmente, devido suas propriedades ansiolíticas e antimicrobianas.

O presente estudo demonstra-se importante, pois permitirá a caracterização das interações entre os flavonoides e as principais proteínas envolvidas na infecção pelo SARS-CoV-2, bem como a avaliação de seus potenciais como candidatos a fármacos. Em virtude disso, a atual pesquisa pode levar a um aumento no número de compostos que possam vir a ser testados para a obtenção de novos agentes terapêuticos com atividade antiviral.

\section{Metodologia}

\subsection{Tipo de estudo}

O presente estudo constitui-se como quantitativo descritivo de caráter experimental. Uma pesquisa de caráter quantitativo foca sobre um problema social ou humano, e se baseia no teste de uma teoria composta por variáveis quantificadas numericamente, aos quais são analisadas de forma matemática, objetivando averiguar se as generalizações supostas em teoria são ou não sustentáveis. Os estudos descritivos exigem do investigador uma gama de informações a respeito do seu alvo de pesquisa. Neste tipo de estudo, o objetivo é realizar uma descrição dos fatos e fenômenos que ocorrem em determinada realidade (Silva, 2016).

\subsection{Procedimentos experimentais}

As etapas realizadas nos processos de acoplamento molecular realizados foram detalhadas a seguir.

\subsubsection{Seleção dos alvos e ligantes}

Para o desenvolvimento do presente trabalho, selecionou-se a ProM e o complexo entre a ECA2 + RBD. Através de revisão de literatura, selecionou-se ainda os flavonoides presentes em maior concentração no óleo essencial das plantas do gênero Lavandula.

\subsubsection{Preparo dos ligantes}

Inicialmente, as estruturas moleculares foram consultadas na base de compostos PubChem, onde realizou-se a obtenção de suas estruturas tridimensionais em formato SDF. Em seguida, as moléculas foram submetidas ao programa Avogadro para otimização conformacional por meio do cálculo de campo de força MMFF94. Posteriormente as moléculas foram salvas em formato do Protein Data Bank (PDB), onde por meio do programa AutoDock Tools definiu-se a fixação da conformação tal qual a gerada no Avogadro, a fim de que o processo de acoplamento molecular não altere a conformação dos ligantes. Por fim, realizou-se a conversão em formato PDBQT, exigido pelo AutoDock Vina para acoplamento. 


\subsubsection{Regra de Lipinski aplicada aos ligantes}

Os flavonoides foram ainda submetidos a testes computacionais para avaliação de suas propriedades moleculares de acordo com a regra de Lipinski, por meio da plataforma MolInspiration (https://www.molinspiration.com/cgi-bin/properties), com o intuito de analisar o potencial das moléculas de serem bons candidatos a novos fármacos.

\subsubsection{Preparo do complexo ECA2+RBD}

O complexo entre as duas proteínas não continha um ligante nativo, por esta razão foi submetido à plataforma PDBsum, a fim de verificar as interações de aminoácidos que ocorriam entre cada proteína. Os aminoácidos que interagiam no complexo proteína-proteína foram selecionados como alvo dos ligantes para o acoplamento molecular, por meio do programa Biovia Discovery Studio (BDS), onde as coordenadas para acoplamento foram definidas, conforme se pode observar na Figura 1 (esfera violeta compreende o campo definido).

Figura 1 - Coordenadas para acoplamento no complexo ECA2 + RBD.

\section{CÓDIGO DE IDENTIFICAÇÃO NO PDB: 6MOJ}

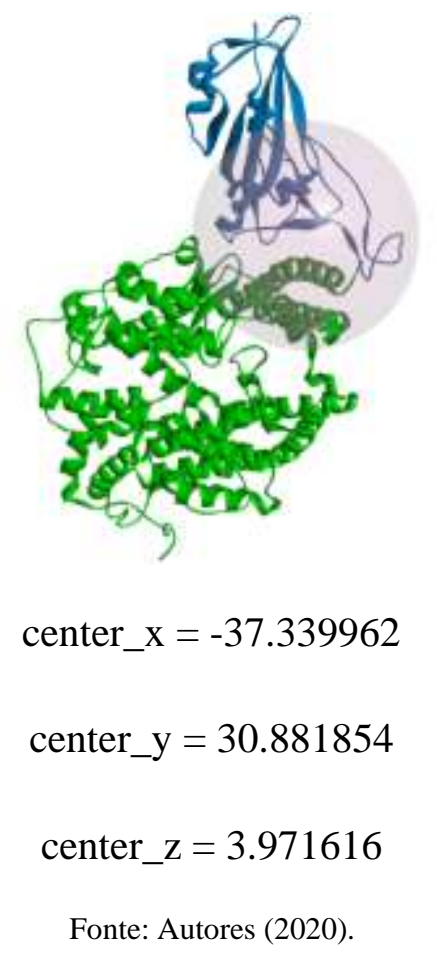

Em seguida, por meio do BDS, procedeu-se para a otimização do complexo, removendo pequenas moléculas que não fizessem parte das proteínas, bem como eliminando moléculas de água e adicionando os hidrogênios polares. Com o BDS, foram definidas as coordenadas que delimitaram a região específica para o acoplamento molecular. Posteriormente as moléculas foram salvas em formado PDB, onde por meio do programa AutoDock Tools realizou-se a conversão em formato PDBQT, exigido pelo AutoDock Vina para acoplamento.

\subsubsection{Preparo da ProM}

De forma semelhante ao complexo, com o uso do programa BDS, foram removidas as águas e moléculas que não pertencessem a ProM. O ligante presente cristalografado na proteína, o Inibidor N3, serviu de base para avaliação dos principais aminoácidos a serem definidos como alvo para o acoplamento das moléculas. Com o BDS, foram definidas as coordenadas que 
delimitaram a região específica para o acoplamento molecular, conforme se pode observar na Figura 2 (esfera violeta compreende o campo definido).

Figura 2 - Coordenadas para acoplamento na ProM.

\section{CÓDIGO DE IDENTIFICAÇÃO NO PDB: 6LU7}

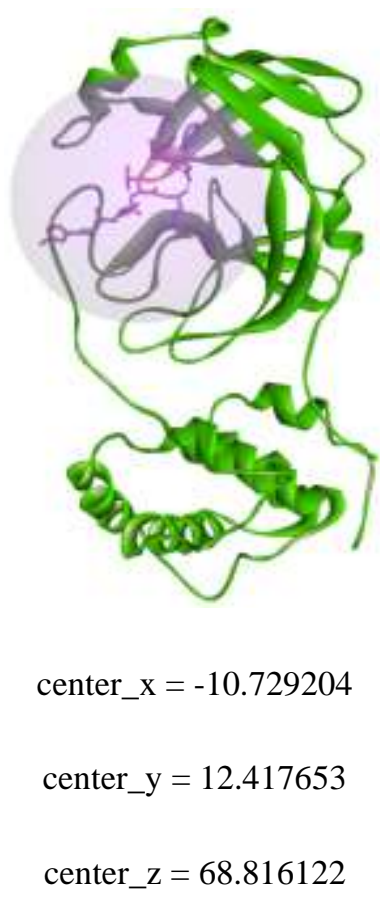

Fonte: Autores (2020).

Realizou-se ainda a adição dos hidrogênios polares na proteína. Posteriormente as moléculas foram salvas em formado PDB, onde por meio do programa AutoDock Tools realizou-se a conversão em formato PDBQT, exigido pelo AutoDock Vina para acoplamento.

\subsubsection{Redocking como método de validação}

Visto que a ProM possuía um ligante co-cristalizado (inibidor N3), realizou-se o redocking, a fim de validar a metodologia de acoplamento. Tal procedimento baseia-se na submissão do ligante co-cristalizado com o receptor aos estudos de acoplamento molecular, com o intuito de observar se as interações com os resíduos de aminoácidos chave e a orientação espacial do ligante se mantêm preservada. Neste procedimento, o Root-Mean-Square-Deviation (RMSD), entre o ligante cristalográfico e o receptor deve ser menor possível (menos de 2,0 angstrons), a fim de comprovar a capacidade preditiva do modelo in silico (Gomes, 2019). A verificação do RMSD foi realizada através do BDS.

\subsection{Análise dos resultados}

Após a finalização do acoplamento, foram selecionadas as conformações de menor energia de ligação em cada complexo ligante-proteína. Para a visualização tridimensional (3D) dos complexos, utilizou-se os programas ChimeraX e BDS. A análise dos complexos formados e suas interações bidimensionais (2D), foi feita por meio do BDS, onde observou-se os tipos de interações envolvidas entre os flavonoides e as proteínas. 


\section{Resultados e Discussão}

A representação 3D de superfície das proteínas selecionadas como alvo para acoplamento pode ser observada na Figura 3.

Figura 3 - Alvos selecionados para acoplamento (representação de superfície).

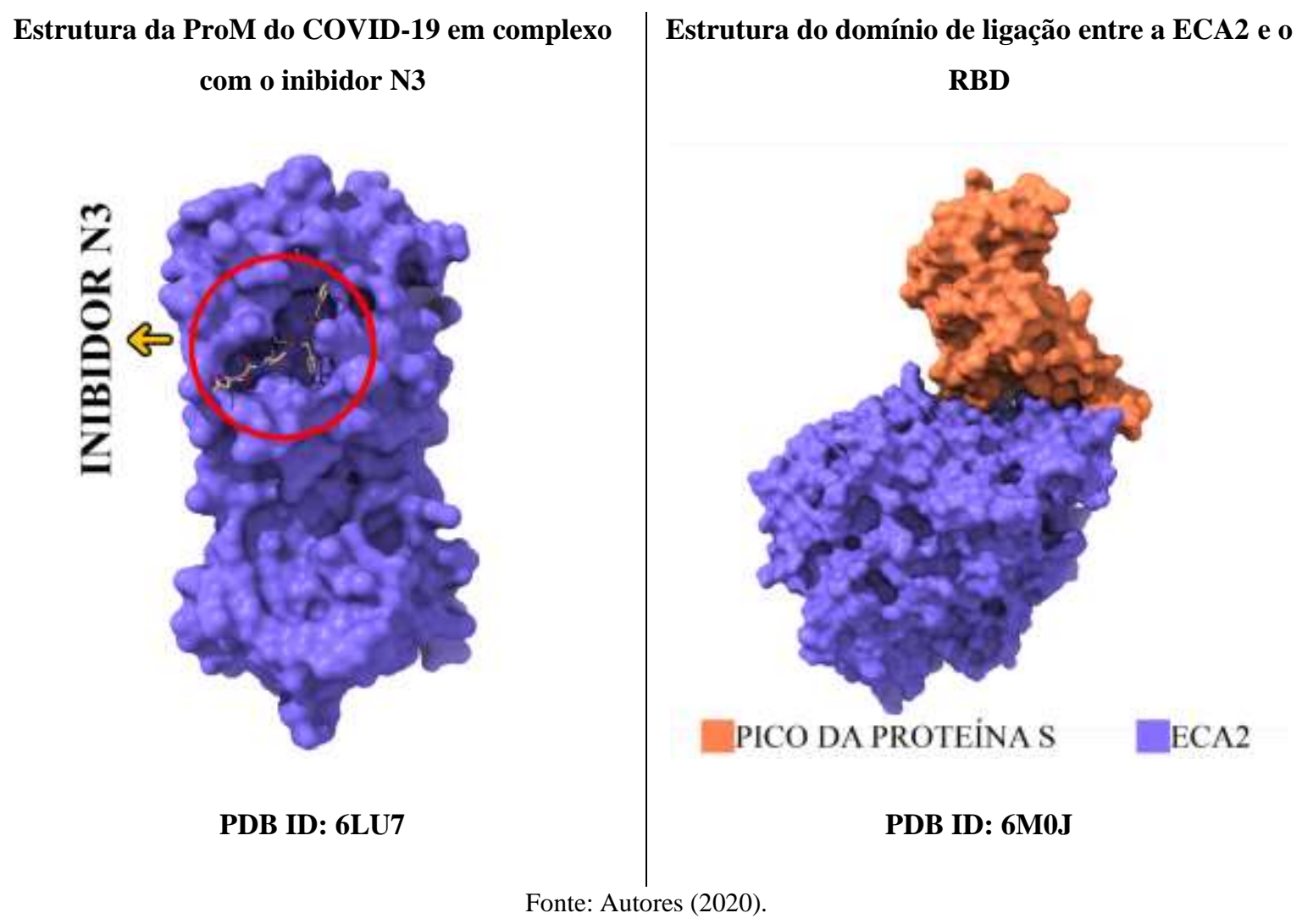

O Inibidor N3 pode ser melhor visualizado na Figura 4.

Figura 4 - Inibidor N3 (visualização 2D à direita e 3D à esquerda).

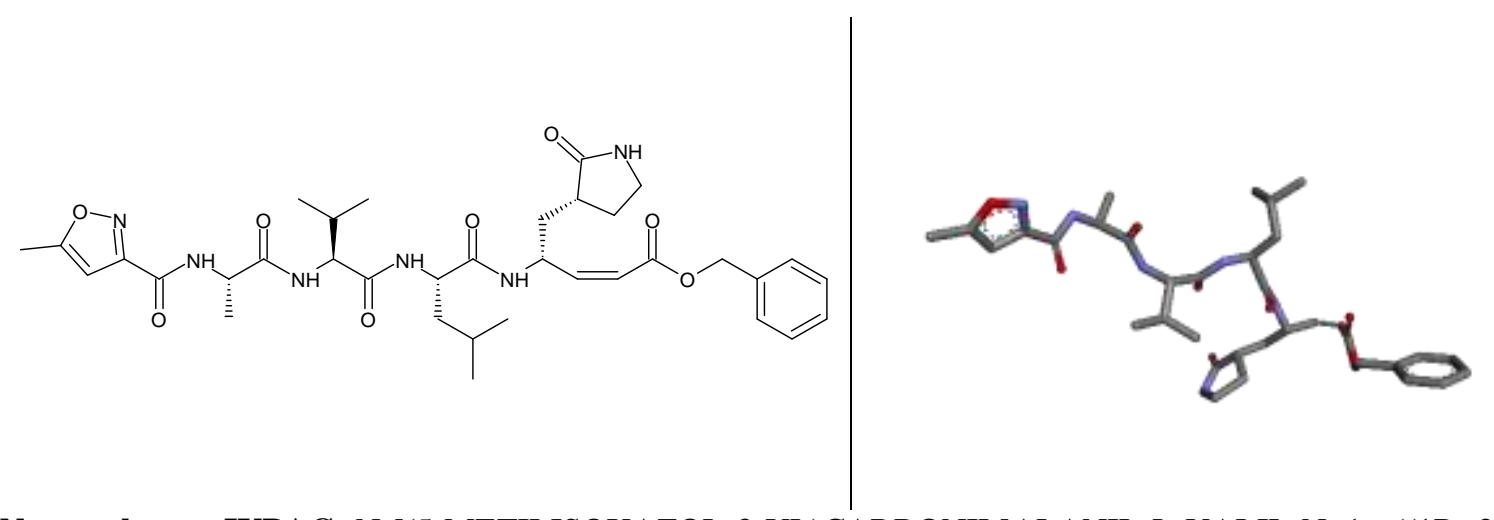

Nomenclatura IUPAC: N-[(5-METILISOXAZOL-3-YL)CARBONIL]ALANIL-L-VALIL-N 1 - ((1R, 2Z)4-(BENZILOXI)-4-OXO-1-\{[(3R)-2-OXOPIRROLIDINA-3-IL]METIL $\}$ BUT-2-ENIL)-L-LEUCINAMIDA. Fonte: Autores (2020).

As interações do Inibidor N3 com a ProM pode ser visualizado de maneira detalhada na Figura 5. 
Figura 5 - Inibidor N3 e suas interações com a ProM do Sars-Cov-2.
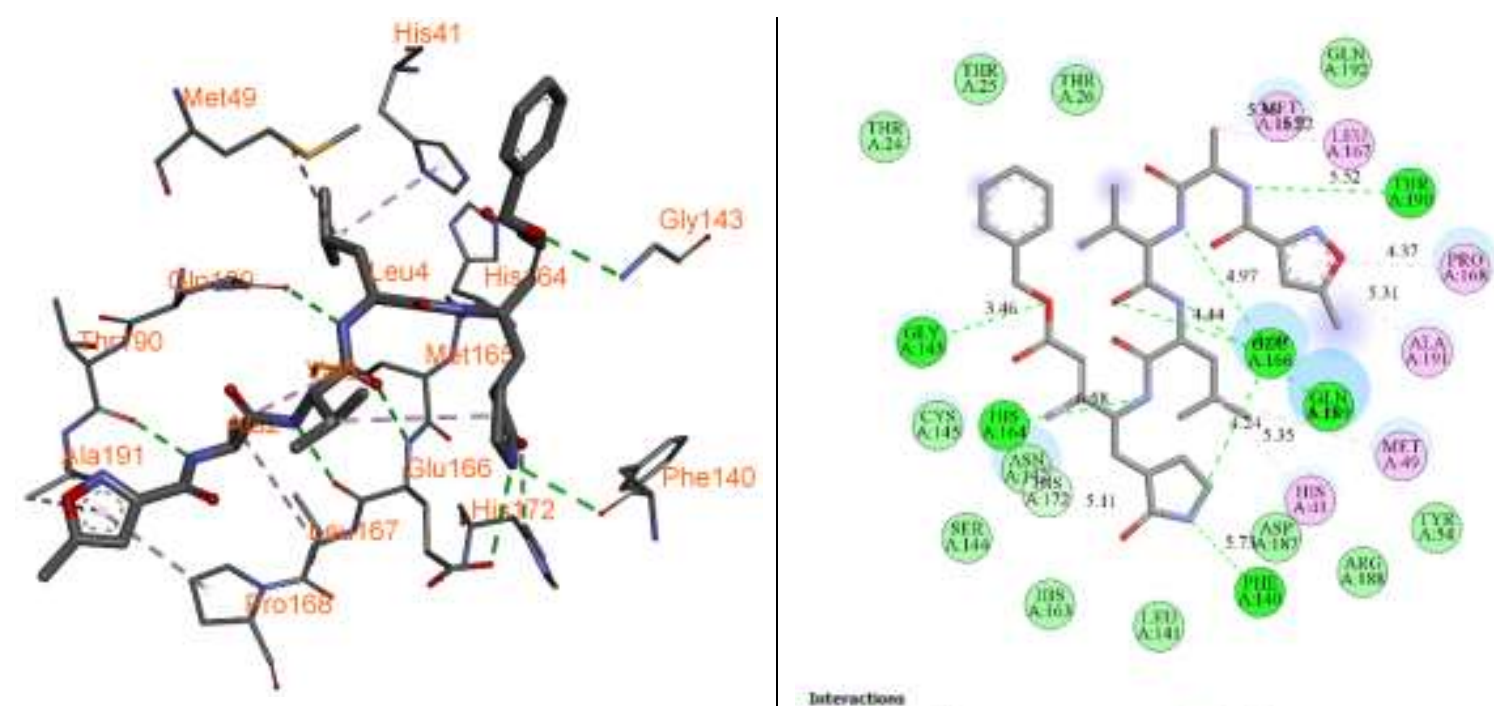

\section{Luteractions}

$[$ w whiter whit:

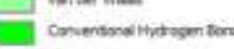

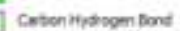

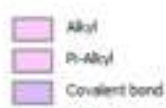

Fonte: Autores (2020).

O Inibidor N3 trata-se de um potente inibidor covalente da ProM, que atua por meio de um mecanismo de inativação irreversível de duas etapas. O N3, associa-se com a ProM formando um complexo inibidor-enzima com uma ligação de equilíbrio constante. A ligação covalente estável é formada entre o inibidor e a ProM via ataque nucleofílico da cisteína catalítica sobre o grupo vinil do N3, caracterizando uma alta taxa de inativação da proteína, ao formar uma ligação tioéter no carbono $\beta$, como pode ser observado na Figura 6 (Frecer \& Miertus, 2020). 
Figura 6 - Formação de ligação com Cys145 e Inibidor N3.<smiles>Cc1cc(C(=O)N[C@@H](C)C(=O)N[C@H](C(=O)N[C@@H](CC(C)C)C(=O)N[C@H](/C=C/C(=O)OCc2ccccc2)C[C@@H]2CCNC2=O)C(C)C)no1</smiles><smiles>NC(CS)C(=O)O</smiles><smiles>C=C(CC(SCC(N)C(=O)O)[C@H](C[C@@H]1CCNC1=O)NC(=O)[C@H](CC(C)C)NC(=O)[C@H](NC(=O)[C@H](C)NC(=O)c1cc(C)on1)C(C)C)OCc1ccccc1</smiles>

Fonte: Autores (2020).

Através do redocking, a metodologia aplicada para ancoramento molecular mostrou-se efetiva, onde a variação do RMSD foi de apenas 1,57 angstrons $(\AA)$. As conformações do ligante no acoplamento cristalográfico e no redocking podem ser observadas na Figura 7. 
Figura 7 - Poses do Inibidor N3 cristalografado com a ProM na forma nativa (em verde) e no redocking (em azul).
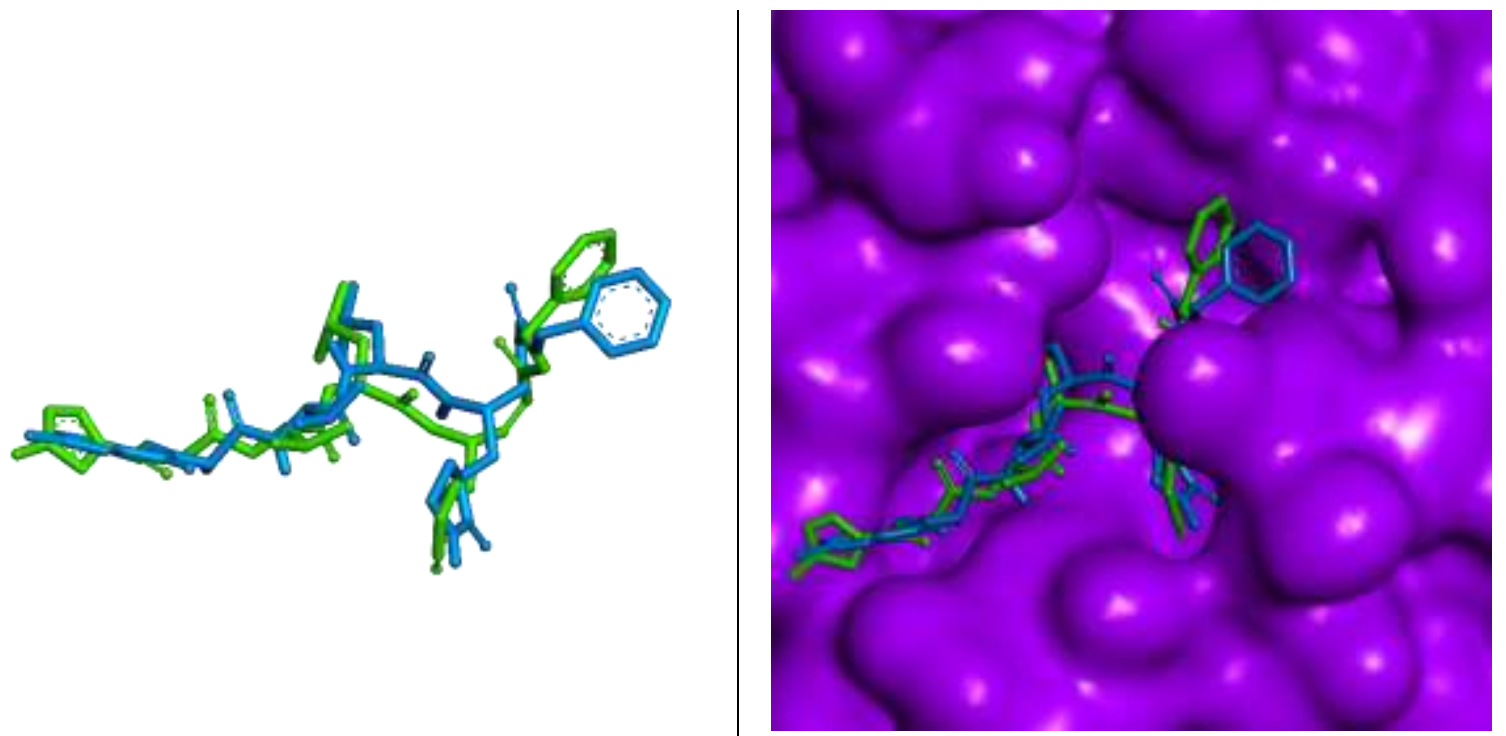

Fonte: Autores (2020).

A Figura 8, representada abaixo, descreve as interações entre a ECA2 e o RBD.

Figura 8 - Interações entre a ECA2 (cadeia A) e o RBD (cadeia E).

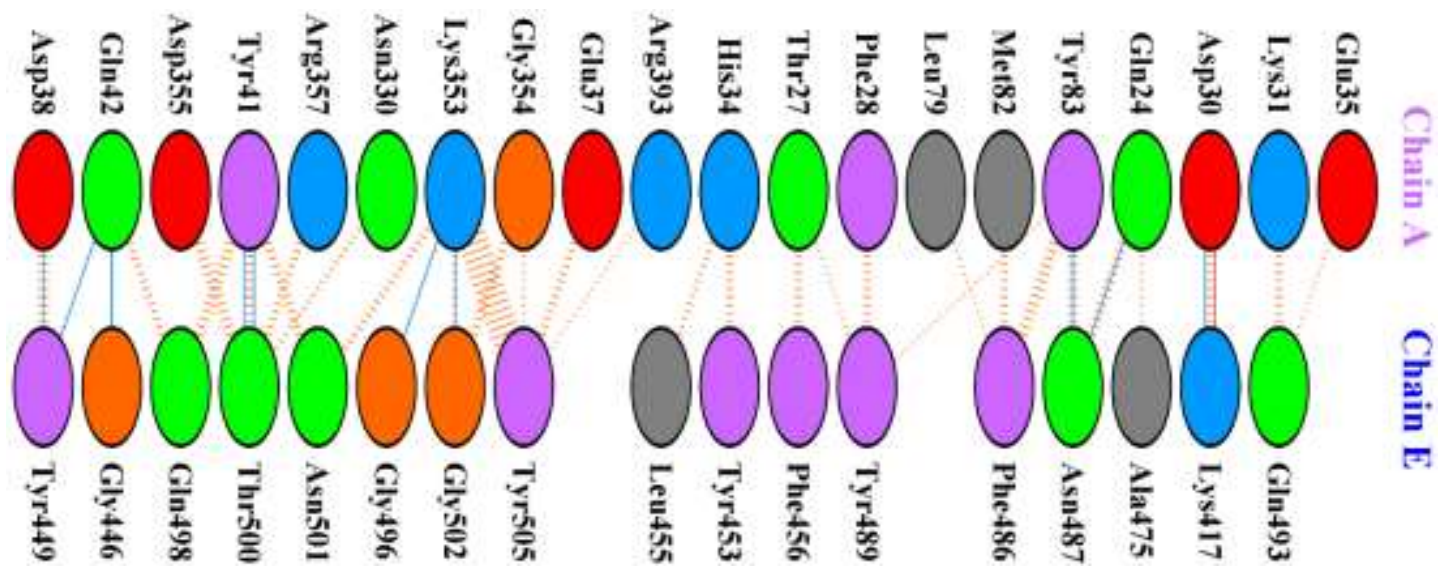

Pontes de Sal Ligações Dissulfeto Ligações de Hidrogênio * * * Contatos não vinculados

\begin{tabular}{c|c|c|c|c|c|c}
\hline CADEIA & $\begin{array}{c}\text { Número de } \\
\text { resíduos de } \\
\text { interface }\end{array}$ & $\begin{array}{c}\text { Área de } \\
\text { interface }(\AA 2)\end{array}$ & $\begin{array}{c}\text { Número de } \\
\text { pontes de sal }\end{array}$ & $\begin{array}{c}\text { Número de } \\
\text { ligações } \\
\text { dissulfeto }\end{array}$ & $\begin{array}{c}\text { Número } \\
\text { ligações de } \\
\text { hidrogênio }\end{array}$ & $\begin{array}{c}\text { Número de } \\
\text { contatos não } \\
\text { vinculados }\end{array}$ \\
\hline A & $\mathbf{2 0}$ & $\mathbf{8 2 5}$ & $\mathbf{1}$ & $\mathbf{0}$ & $\mathbf{1 0}$ & $\mathbf{1 0 1}$ \\
\hline E & $\mathbf{1 7}$ & $\mathbf{8 6 3}$ & & & \\
\hline
\end{tabular}

Fonte: Adaptado de PDBsum (2020).

Os aminoácidos-chave para a inibição da ProM foram aqueles que interagiam com o composto N3. Já na ECA2 e no RBD, foram selecionados os aminoácidos que realizavam interações entre as proteínas. Tais dados podem ser observados no Quadro 1. 
Quadro 1 - Aminoácidos-chave em cada proteína analisada.

\begin{tabular}{c|c|c}
\hline ProM & ECA2 & RBD \\
\hline Thr24, Thr25, Thr26, Met165, & Asp38, Glu42, Asp355, Tyr41, & Tyr449, Gly446, Gln498, Thr500, \\
Leu167, Gln192, Thr190, Pro168, & Arg357, Asn330, Lys353, Gly354, & Asn501, Gly496, Gly502, Tyr505, \\
Ala191, Glu166, Gln189, Met49, & Glu37, Arg393, His34, Thr27, & Leu455, Tyr453, Phe456, Tyr489, \\
Tyr54, His41, Asp187, Arg188, & Phe28, Leu79, Met82 Tyr83, & Phe486, Asn487, Ala475, Lys417, \\
Phe140, Leu141, His163, His172, & Gln24, Asp30, Lys31, Glu35 & Gln493 \\
Asn142, Cys145, Ser144, His164, & & \\
Cys145, Gly143 & & \\
\hline
\end{tabular}

Fonte: Autores (2020).

Análises estruturais da ProM do SARS-CoV-2 revelaram que o local do sítio ativo permanece o mesmo da ProM do SARS-CoV de 2003. O sítio localiza-se em uma fenda com domínios para uma díade catalítica (His41 e Cys145). A estrutura da ProM ligada com o Inibidor N3 revela que tais aminoácidos são cruciais para o reconhecimento do substrato, juntamente com a Tyr161 e His163 (Mirza \& Froeyen, 2020).

Análises estruturais das Proteínas S do SARS-CoV e SARS-CoV-2 indicam que o RBD apresenta de 73 a $76 \%$ de similaridade estrutural entre as variantes do coronavírus. Quatorze resíduos de aminoácidos foram identificados como essenciais na interação com a ECA2 no SARS-CoV, sendo a Tyr436, Tyr440, Tyr442, Leu443, Leu472, Asn473, Tyr475, Asn479, Gly482, Tyr484, Thr486, Thr487, Gly488 e Tyr491. Já no SARS-CoV-2, apenas oito aminoácidos são conservados, sendo a Tyr449, Tyr453, Asn487, Tyr489, Gly496, Thr500, Gly502 e Tyr505. Na ECA2, os aminoácidos mais importantes para o acoplamento viral foram definidos como a Lys31 e Lys353 (Ali \& Vijayan, 2020).

Conforme Lis-Balchin (2002), os principais flavonoides encontrados no gênero Lavandula, são a Delfinidina, Escutelarina, Hipoaletina, Malvidina, Salvigenina e Xantomicrol. Suas nomenclaturas de acordo com União Internacional de Química Pura e Aplicada (IUPAC) e códigos na plataforma PubChem podem ser encontrados no Quadro 2.

Quadro 2 - Principais flavonoides encontrados nas folhas de lavanda.

\begin{tabular}{|c|c|c|}
\hline $\begin{array}{c}\text { PUBCHEM } \\
\text { ID }\end{array}$ & $\begin{array}{c}\text { NOMENCLATURA } \\
\text { IUPAC }\end{array}$ & $\begin{array}{c}\text { NOMENCLATURA } \\
\text { USUAL }\end{array}$ \\
\hline 5281648 & 2- (3,4-dihidroxifenil)-5,7,8-trihidroxicromen-4-ona & Hipoaletina \\
\hline 5281697 & 5,6,7-trihidroxi-2-(4-hidroxifenil)cromen-4-ona & Escutelarina \\
\hline 73207 & 5-hidroxi-2-(4-hidroxifenil)-6,7,8-trimetoxicromen-4-ona & Xantomicrol \\
\hline 161271 & 5-hidroxi-6,7-dimetoxi-2-(4-metoxifenil)cromen-4-ona & Salvigenina \\
\hline 128853 & 2-(3,4,5-trihidroxifenil)cromenilio-3,5,7-triol & Delfinidina \\
\hline 159287 & 2-(4-hidroxi-3,5-dimetoxifenil)cromenílio-3,5,7-triol & Malvidina \\
\hline
\end{tabular}

Fonte: Autores (2020).

As estruturas 2D dos flavonoides também foram representadas e encontram-se presentes na Figura 9. 
Figura 9 - Representação 2D dos flavonoides selecionados para acoplamento.<smiles>O=C1CC(c2ccc(O)c(O)c2)Oc2c(O)c(O)cc(O)c21</smiles>

HIPOALETINA<smiles>COc1c(OC)c(O)c2c(=O)cc(-c3ccc(O)cc3)oc2c1OC</smiles>

XANTOMICROL<smiles>Oc1cc(O)c2cc(O)c(-c3cc(O)c(O)c(O)c3)[o+]c2c1</smiles>

DELFINIDINA<smiles>O=C1CC(c2ccc(O)cc2)Oc2cc(O)c(O)c(O)c21</smiles>

ESCUTELARINA<smiles>COc1ccc(C2CC(=O)c3c(cc(OC)c(OC)c3O)O2)cc1</smiles>

SALVIGENINA<smiles>COc1cc(C2=C3C=C(O)C=C(O)C(=[O+]3)C=C(O)O2)cc(OC)c1O</smiles>

MALVIDINA

Fonte: Autores (2020).

Os ligantes foram submetidos à regra de Lipinski para verificar seu potencial como fármacos promissores, principalmente por via oral. Os resultados obtidos encontram-se na Tabela 1. 
Tabela 1 - Parâmetros da Regra de Lipinski aplicada aos flavonoides.

\begin{tabular}{cccccc}
\hline MOLÉCULA & $\begin{array}{c}\text { LogP } \\
(\geq \mathbf{5})\end{array}$ & $\begin{array}{c}\text { MASSA } \\
\text { MOLECULAR } \\
(\leq \mathbf{5 0 0})(\mathbf{g} / \mathbf{m o l})\end{array}$ & $\begin{array}{c}\text { ACEPTORES DE } \\
\text { LIGAÇÕES DE } \\
\text { HIDROGÊNIO }(\leq \mathbf{1 0})\end{array}$ & $\begin{array}{c}\text { DOADORES DE } \\
\text { LIGAÇÕES DE } \\
\text { HIDROGÊNIO ( } \mathbf{5})\end{array}$ \\
\hline Delfinidina & -1.04 & 338.70 & 7 & 6 \\
\hline Escutelarina & 2.20 & 286.24 & 6 & 4 \\
\hline Hipoaletina & 1.71 & 302.24 & 7 & 5 \\
\hline Malvidina & -0.42 & 331.30 & 7 & 1 \\
\hline Salvigenina & 3.32 & 328.32 & 6 & 2 \\
\hline Xantomicrol & 2.97 & 344.32 & 7 & \\
\hline & & &
\end{tabular}

Fonte: Autores (2020).

Comparando-se os parâmetros obtidos com a Regra de Lipinski, nota-se que todos os compostos violaram a regra do $\operatorname{LogP}$, apresentando resultados abaixo do mínimo recomendado. Quanto à massa molecular, todas as moléculas encontram-se dentro da margem proposta, assim como no parâmetro de aceptores de ligações de hidrogênio, onde todas as moléculas obtiveram resultado favorável a regra. Por fim, quanto ao parâmetro de doação de ligações de hidrogênio, apenas a Delfinidina violou tal regra, apresentando um doador acima do valor de referência.

Tendo em vista que para ser considerado um bom candidato a fármaco e com biodisponibilidade oral favorável, as moléculas só podem violar apenas uma das quatro regras. Neste contexto, a Delfinidina apresenta-se como um candidato não promissor, pois violou duas das quatro regras. Todos os demais flavonoides testados encontram-se dentro da margem aceitável pela regra, violando apenas um dos parâmetros, sendo relativo ao LogP.

Logo em seguida, procedeu-se a realização do acoplamento molecular. Após a finalização, os valores de menor energia nas interações entre os flavonoides com as macromoléculas foram registrados e encontram-se presentes na Tabela 2.

Tabela 2 - Valores de menor energia de afinidade entre os flavonoides e proteínas.

\begin{tabular}{|c|c|c|c|c|}
\hline FLAVONOIDE & PROTEÍNA & $\begin{array}{l}\text { AFINIDADE } \\
\text { (kcal/mol) }\end{array}$ & PROTEÍNA & $\begin{array}{c}\text { AFINIDADE } \\
\text { (kcal/mol) }\end{array}$ \\
\hline DELFINIDINA & \multirow{6}{*}{ ProM } & -7.2 & \multirow{6}{*}{$\begin{array}{l}\text { COMPLEXO } \\
\text { ECA2 + RBD }\end{array}$} & -8.0 \\
\hline ESCUTELARINA & & -8.1 & & -7.4 \\
\hline HIPOALETINA & & -7.4 & & -8.3 \\
\hline MALVIDINA & & -6.9 & & -6.8 \\
\hline SALVIGENINA & & -7.2 & & -7.5 \\
\hline XANTOMICROL & & -7.0 & & -7.7 \\
\hline
\end{tabular}

Fonte: Autores (2020).

Nota-se que para a ProM, os flavonoides com os menores valores de energia e consequentemente melhor afinidade, foram a Escutelarina e a Hipoaletina. Já analisando os valores para o complexo da ECA2 + RBD, observa-se que a Hipoaletina, Delfinidina e Xantomicrol apresentaram afinidades mais significativas. A seguir, são representadas nas Figuras 10 e 11 os encaixes entre os flavonoides com a ProM, bem como do complexo ECA2 + RBD, em modelo de superfície. 
Figura 10 - Flavonoides complexados com a ProM.

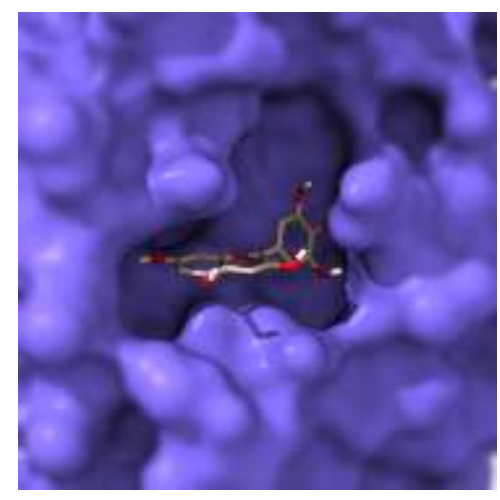

DELFINIDINA

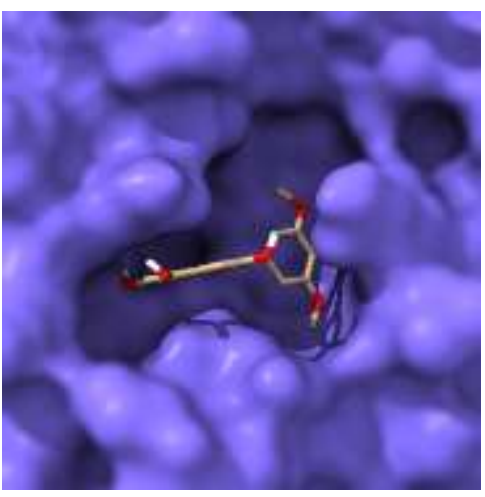

MALVIDINA

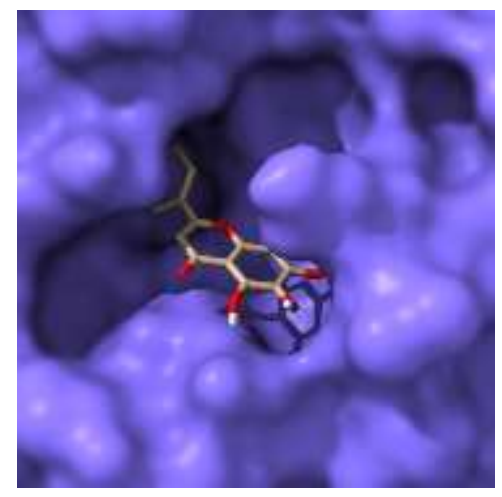

ESCUTELARINA

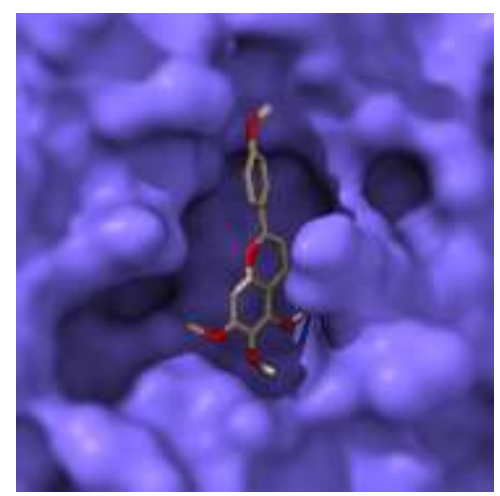

SALVIGENINA

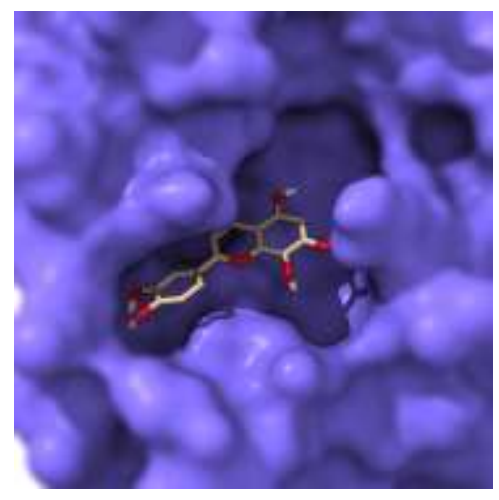

HIPOALETINA

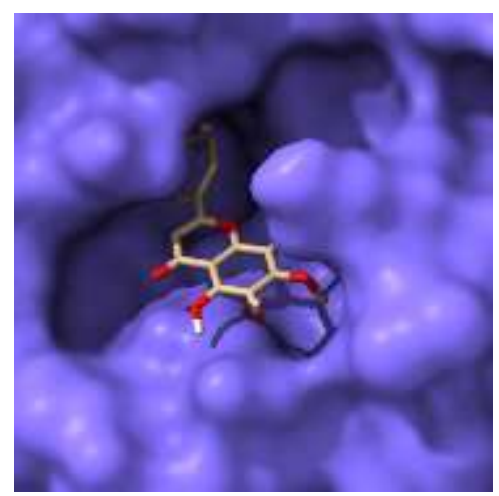

XANTOMICROL

Fonte: Autores (2020). 
Figura 11 - Flavonoides no complexo ACE2 (azul) e o RBD (salmão).

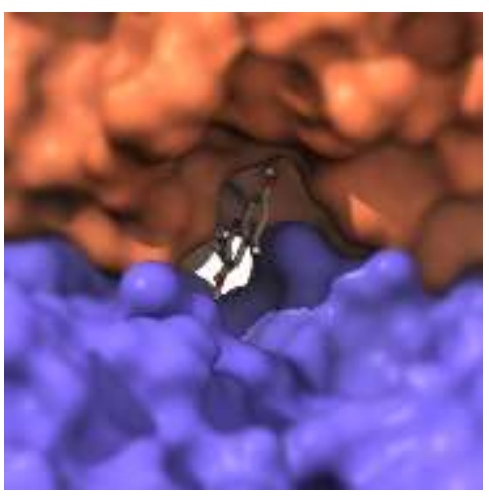

DELFINIDINA

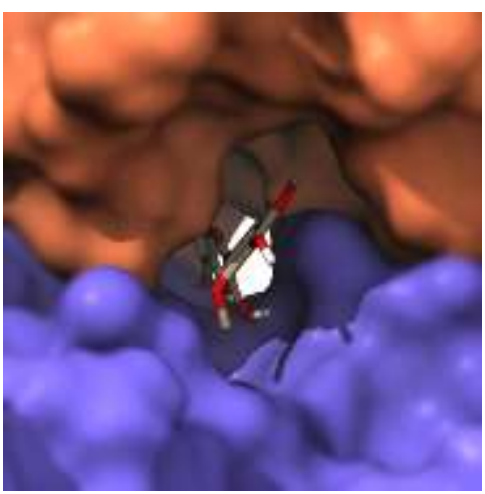

MALVIDINA

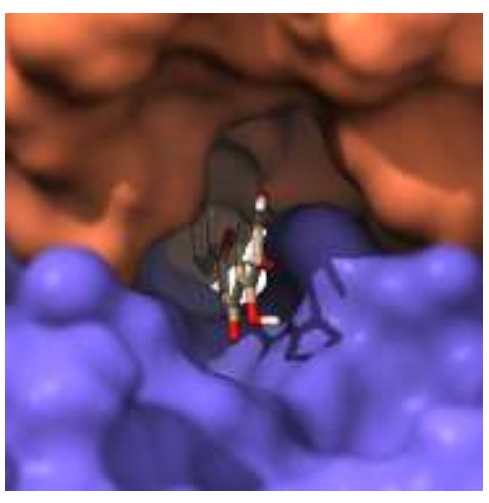

ESCUTELARINA

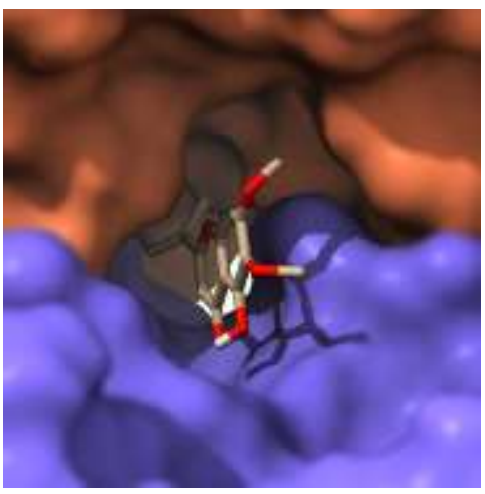

SALVIGENINA

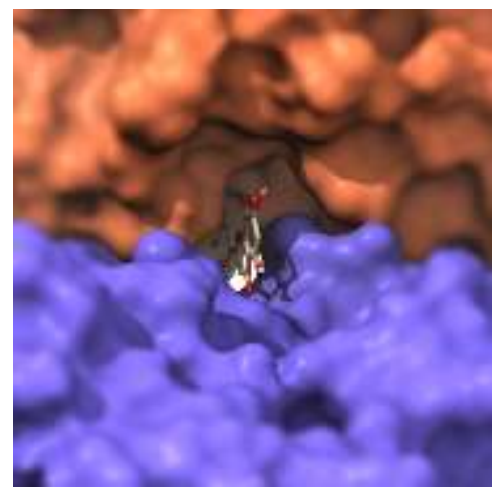

HIPOALETINA

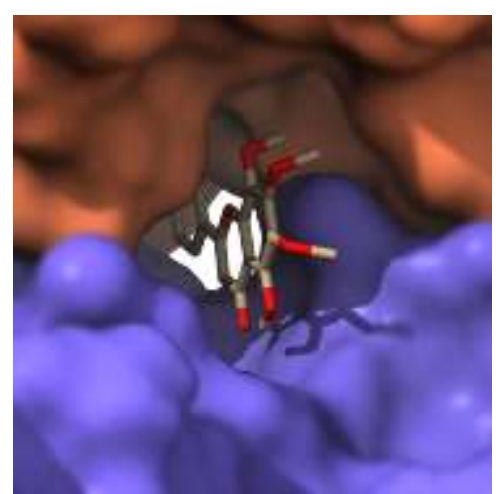

XANTOMICROL

Fonte: Autores (2020).

A seguir, são representadas de maneira detalhada as interações entre os flavonoides com as proteínas alvos do acoplamento.

A Delfinidina, Figura 12, apresenta interações com apenas dois dos quatro aminoácidos definidos como essenciais na ProM, sendo a Cys145 e a His163, contudo, faz uma ligação não favorável com esta última, sendo do tipo aceptor-aceptor, onde a interação entre o Nitrogênio do grupo imina da His 163 com o Oxigênio da Hidroxila no flavonoide apresenta pares de elétrons com possibilidade de doação tornando a interação desfavorável. 
Figura 12 - Interações da Delfinidina com a ProM do SARS-CoV-2.

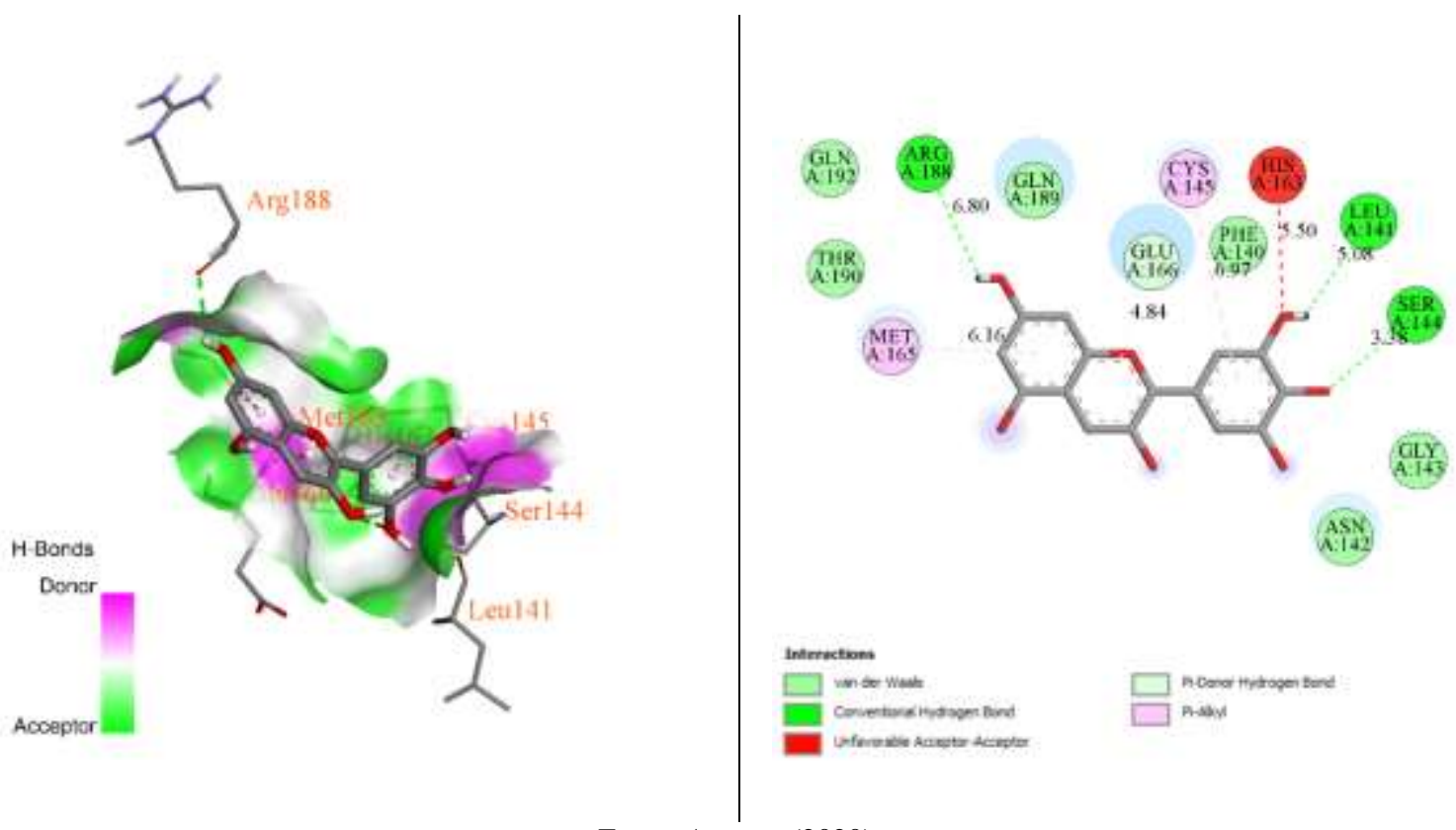

Fonte: Autores (2020).

As interações da Escutelarina com a ProM, observadas na Figura 13, apontam que a molécula interage com três dos quatro aminoácidos principais, sendo a Cys145, His163 e His41. Ainda que suas interações com aminoácidos de importância sejam superiores à Delfinidina, a Escutelarina também apresenta interação não favorável, sendo do tipo aceptor-aceptor com a Leu141. De modo análogo à Delfinidina, a ligação desfavorável ocorre devido à presença de elétrons com possibilidade de doação, nos grupos carbonila da Leu141 com o Oxigênio da Hidroxila.

Figura 13 - Interações da Escutelarina com a ProM do SARS-CoV-2.
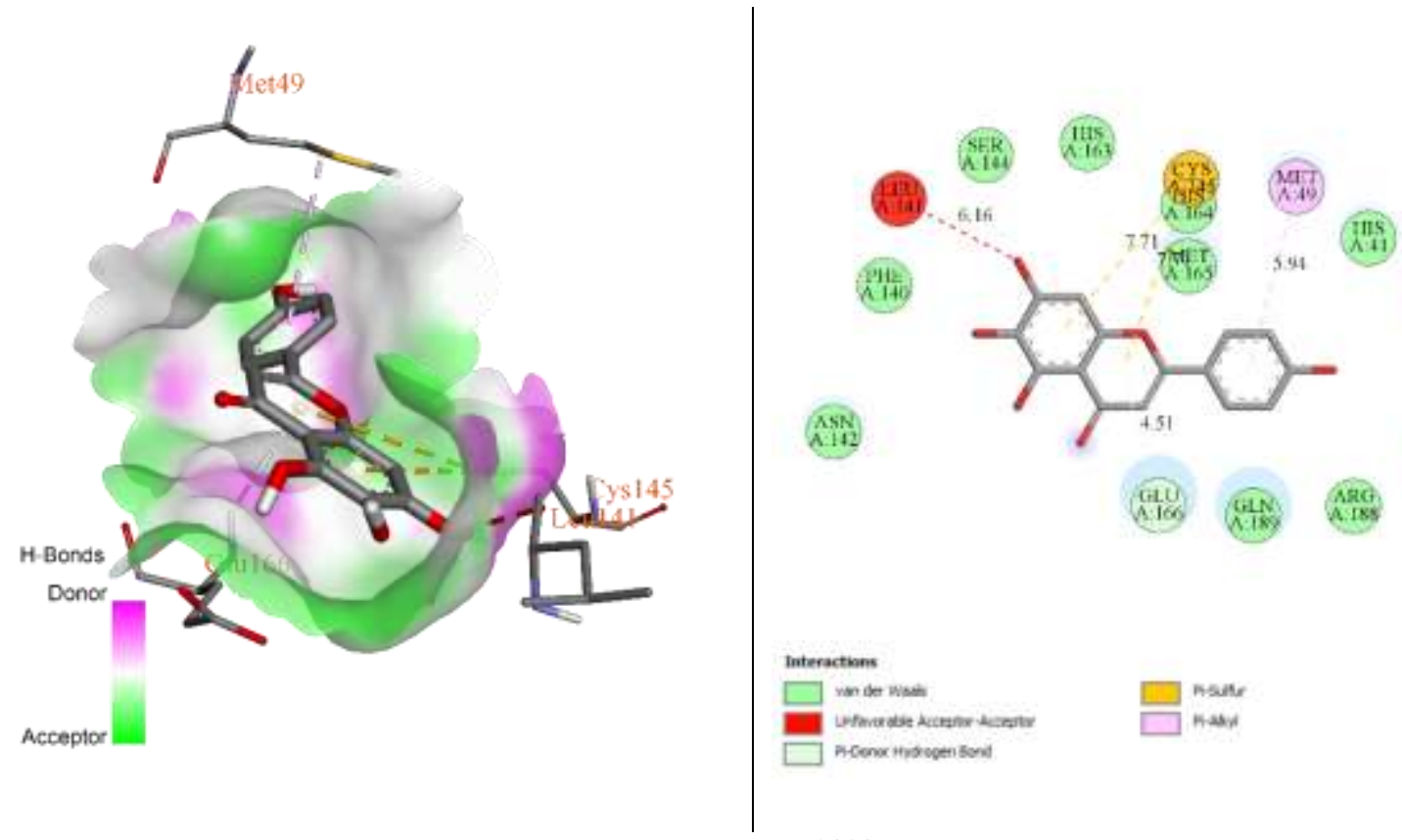

Fonte: Autores (2020).

A Hipoaletina representada na Figura 14, interage com dois dos quatro aminoácidos principais identificados, sendo a His41 e a Cys145. A molécula assim como Delfinidina e Escutelarina, também apresenta uma interação não favorável com um 
aminoácido da ProM, sendo a Arg188, do tipo aceptor-aceptor. Semelhante a Escutelarina, a interação desfavorável ocorre em virtude da interação do grupo Carbonila da Arg188 com o Oxigênio da Hidroxila, onde ambos possuem pares de elétrons com possibilidade de doação.

Figura 14 - Interações da Hipoaletina com a ProM do SARS-CoV-2.

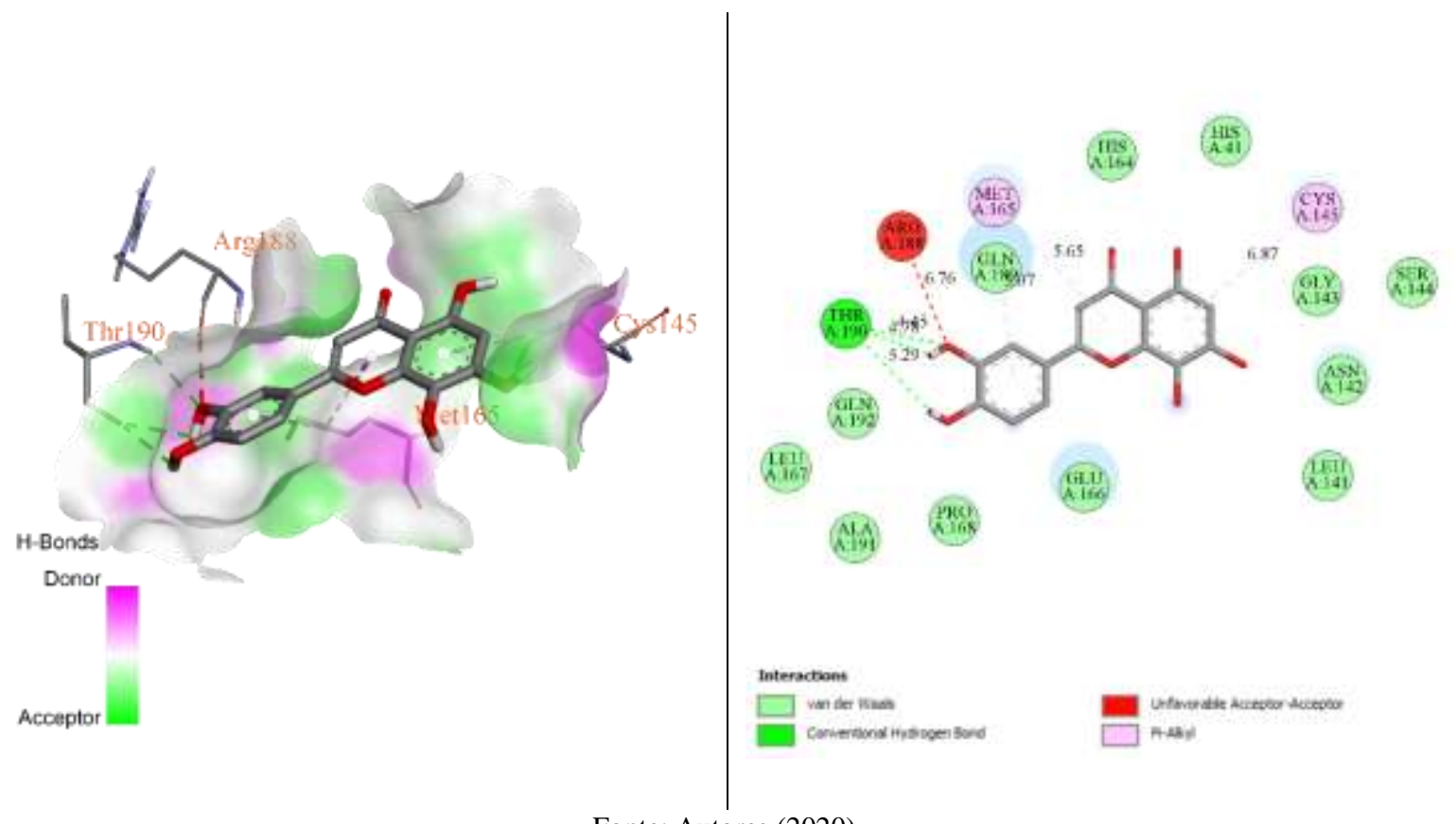

Fonte: Autores (2020).

Ao analisar as interações da Malvidina com a ProM, presentes na Figura 15, observa-se que a mesma realiza interações com três dos quatro aminoácidos de maior importância, sendo a His41, Cys145 e His163, além de não apresentar interações não favoráveis, o que configura uma molécula mais promissora que as antecessoras, ainda que não tenha obtido uma pontuação de afinidade tão alta em comparação às demais.

Figura 15 - Interações da Malvidina com a ProM do SARS-CoV-2.
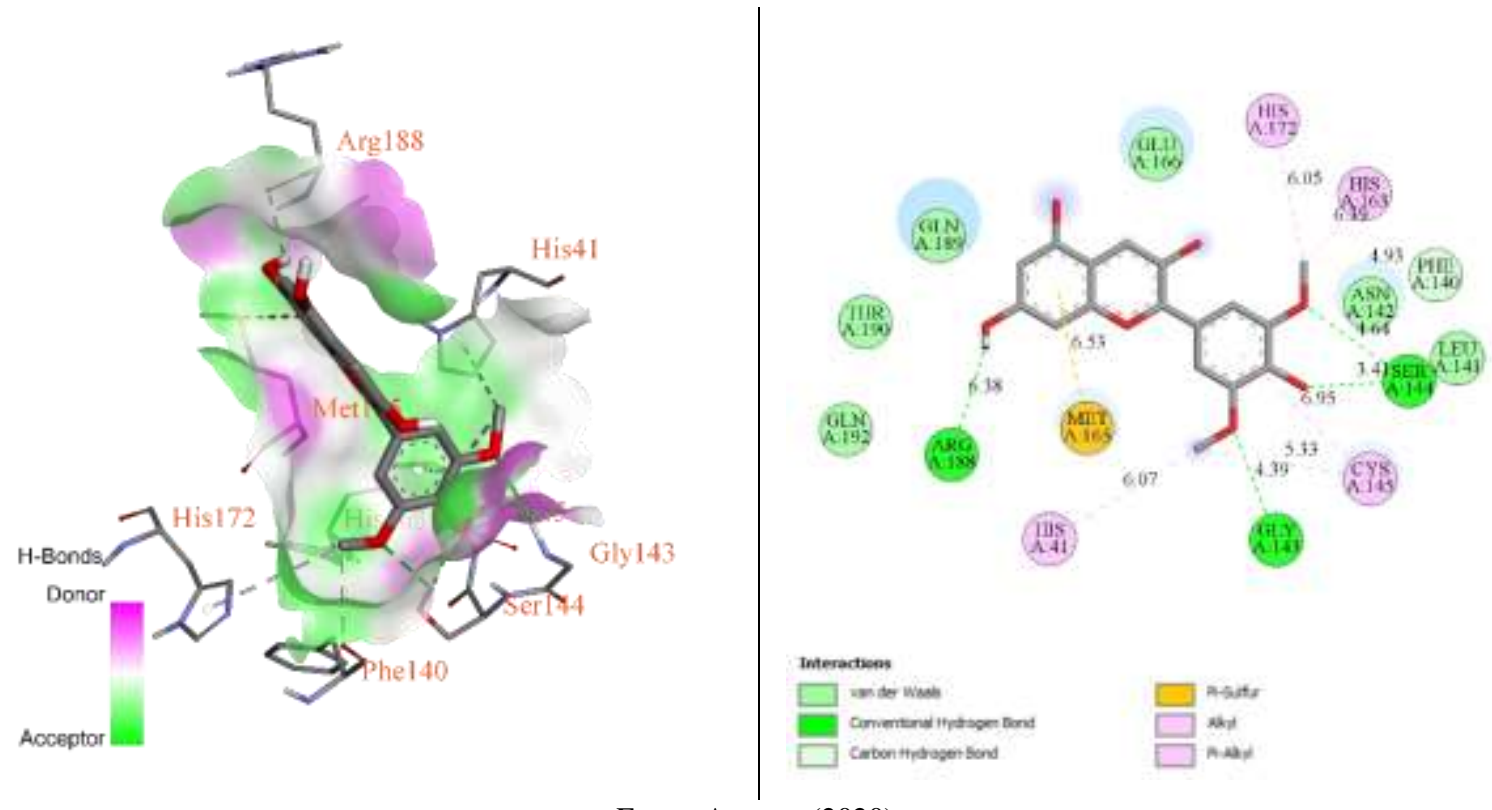

Fonte: Autores (2020). 
A Salvigenina, Figura 16, interage com apenas dois dos quatro aminoácidos principais do sítio ativo da ProM, sendo a His163 e a Cys145. A molécula realiza ainda uma interação não favorável do tipo doador-doador com a Ser144. A interação desfavorável ocorre em virtude do Hidrogênio da Hidroxila no flavonoide e o Hidrogênio da Ser144, serem doadores de prótons.

Figura 16 - Interações da Salvigenina com a ProM do SARS-CoV-2.
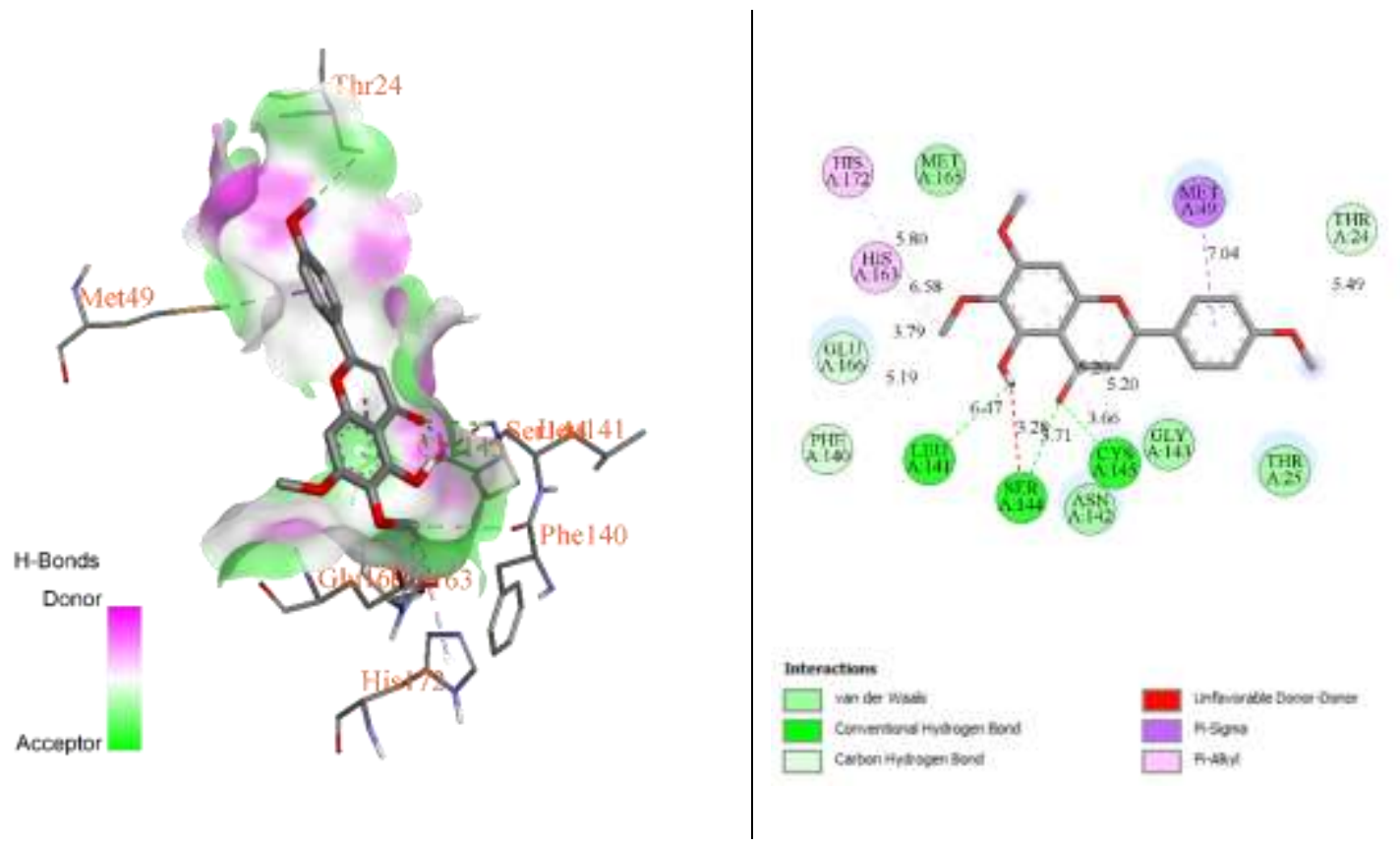

Fonte: Autores (2020).

O Xantomicrol, presente na Figura 17, interage de maneira favorável com três dos quatro aminoácidos principais da ProM, sendo a His41, Cys145 e His163, além de não apresentar interações do tipo não favorável, apresenta-se como uma molécula promissora, com um bom perfil de interações.

Figura 17 - Interações do Xantomicrol com a ProM do SARS-CoV-2.
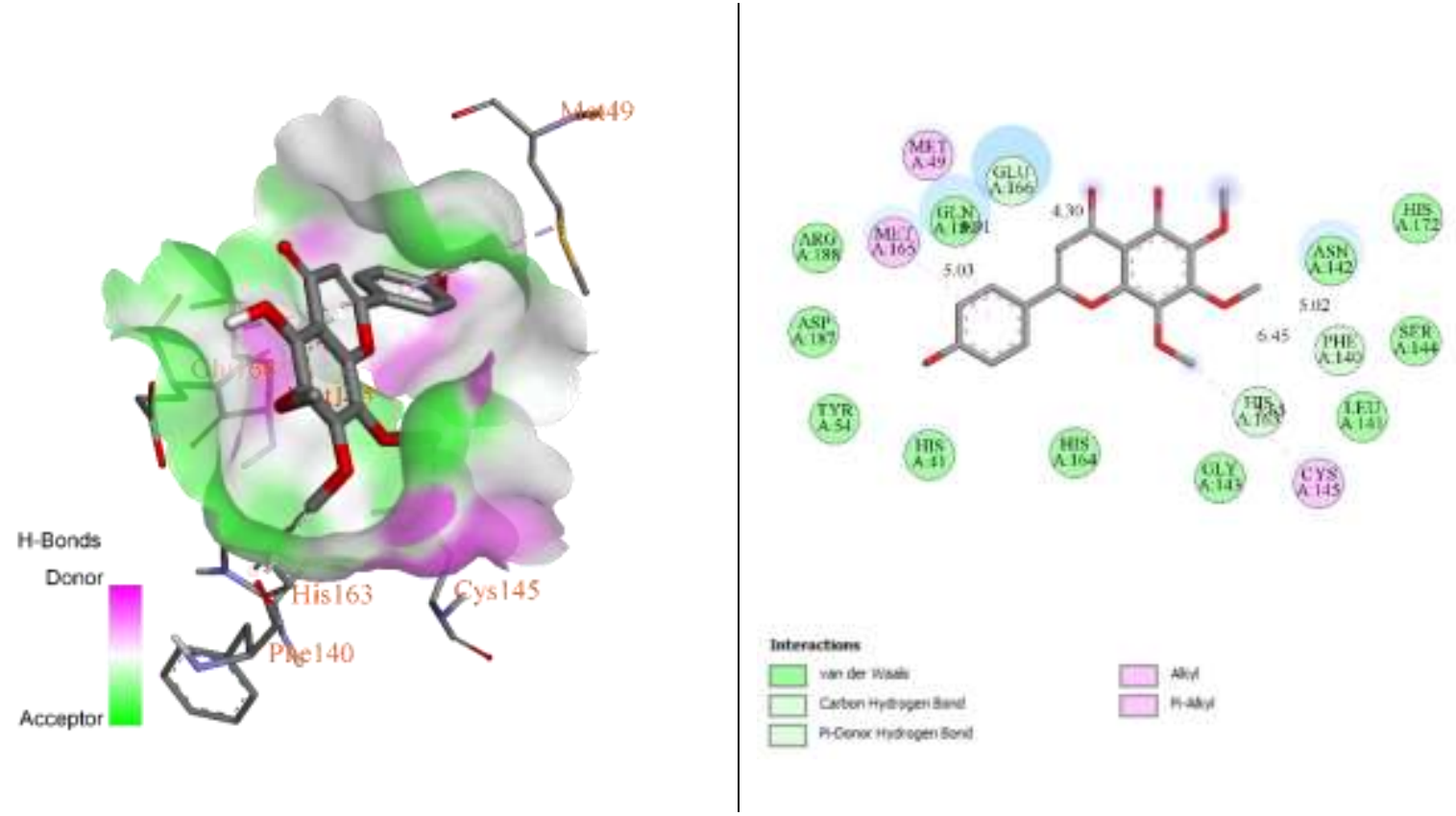

Fonte: Autores (2020). 
Nota-se que os flavonoides Escutelarina, Malvidina e Xantomicrol desempenharam as melhores interações com os aminoácidos-chave da ProM. A Escutelarina, ainda que apresente uma ligação não favorável, realiza uma interação do tipo pienxofre com a Cys145, aminoácido importante na díade catalítica para a inibição efetiva da ProM. Malvidina e Xantomicrol apresentam bom perfil de interações com os resíduos-chave, não ocorrendo interações desfavoráveis.

Considerando os aminoácidos-chave na interação entre RBD e ECA2, nota-se que a Delfinidina (Figura 18), realiza interações com quatro dos principais aminoácidos do RBD, sendo a Tyr449, Tyr453, Gly496 e Tyr505, sendo ligações de van der Waals e de hidrogênio. Já com a ECA2, o flavonoide interage apenas com um dos resíduos principais, a Lys353, por meio de ligação de hidrogênio. Nota-se ainda que o complexo formado possui uma interação não favorável com a Gln409, do tipo doador-doador. A interação ocorre entre átomos de hidrogênio da Gln409 com a Hidroxila do flavonoide.

Figura 18 - Interações da Delfinidina com a ECA2 e o RBD.
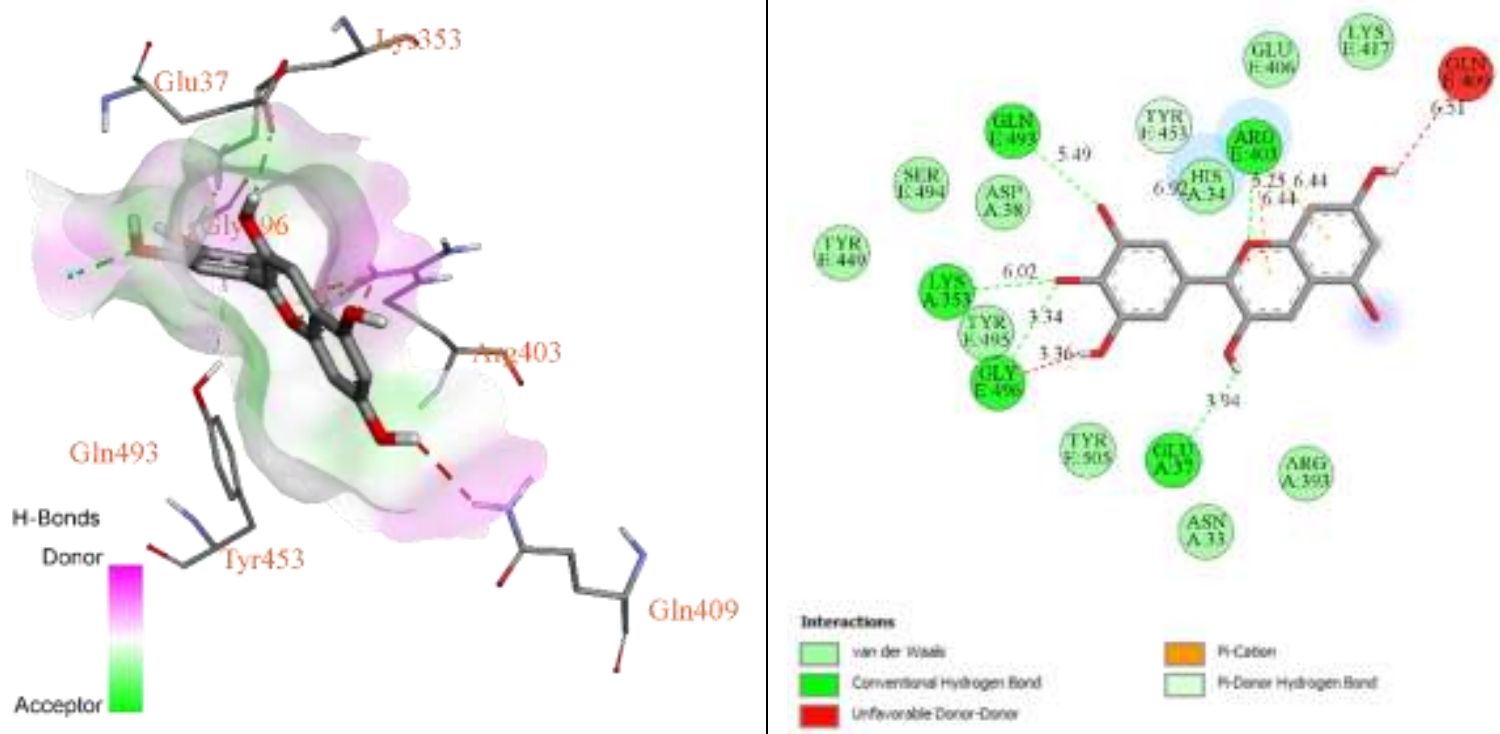

Fonte: Autores (2020).

A Escutelarina, Figura 19 interage com apenas três dos aminoácidos principais do RBD, sendo a Tyr453, Gly496 e Tyr505, sendo todas do tipo van der Waals. Com a ECA2, a molécula realiza interação apenas com a Lys353, do tipo ligação de hidrogênio. 
Figura 19 - Interações da Escutelarina com a ECA2 e o RBD.

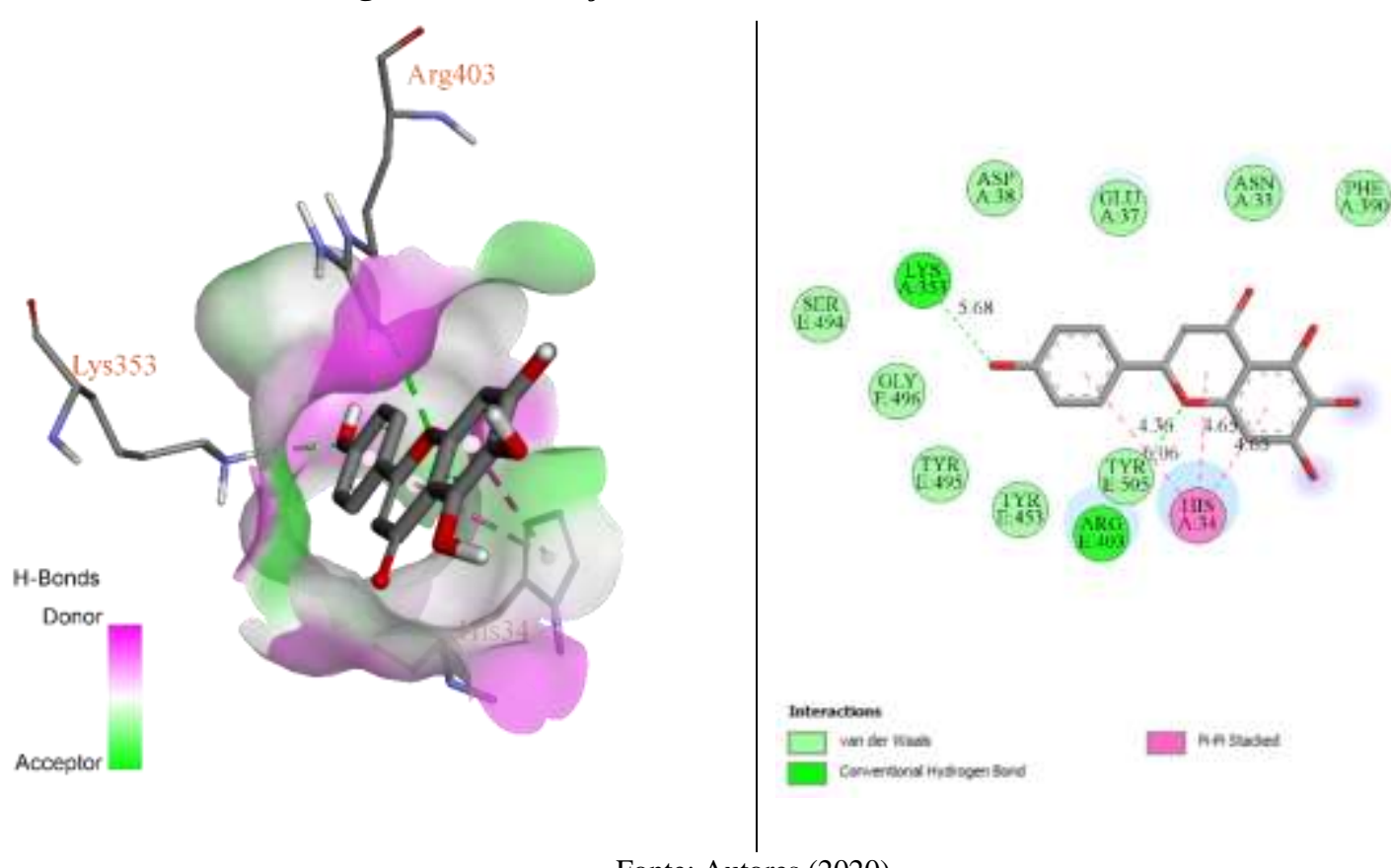

Fonte: Autores (2020).

No complexo com a Hipoaletina, Figura 20, notam-se interações de van der Waals com os aminoácidos Tyr453 e Tyr 505, além de ligações de hidrogênio com a Gly496, todos os aminoácidos do RBD. Com a ECA2, a molécula interage apenas por meio de ligação de van der Waals.

Figura 20 - Interações da Hipoaletina com a ECA2 e o RBD.
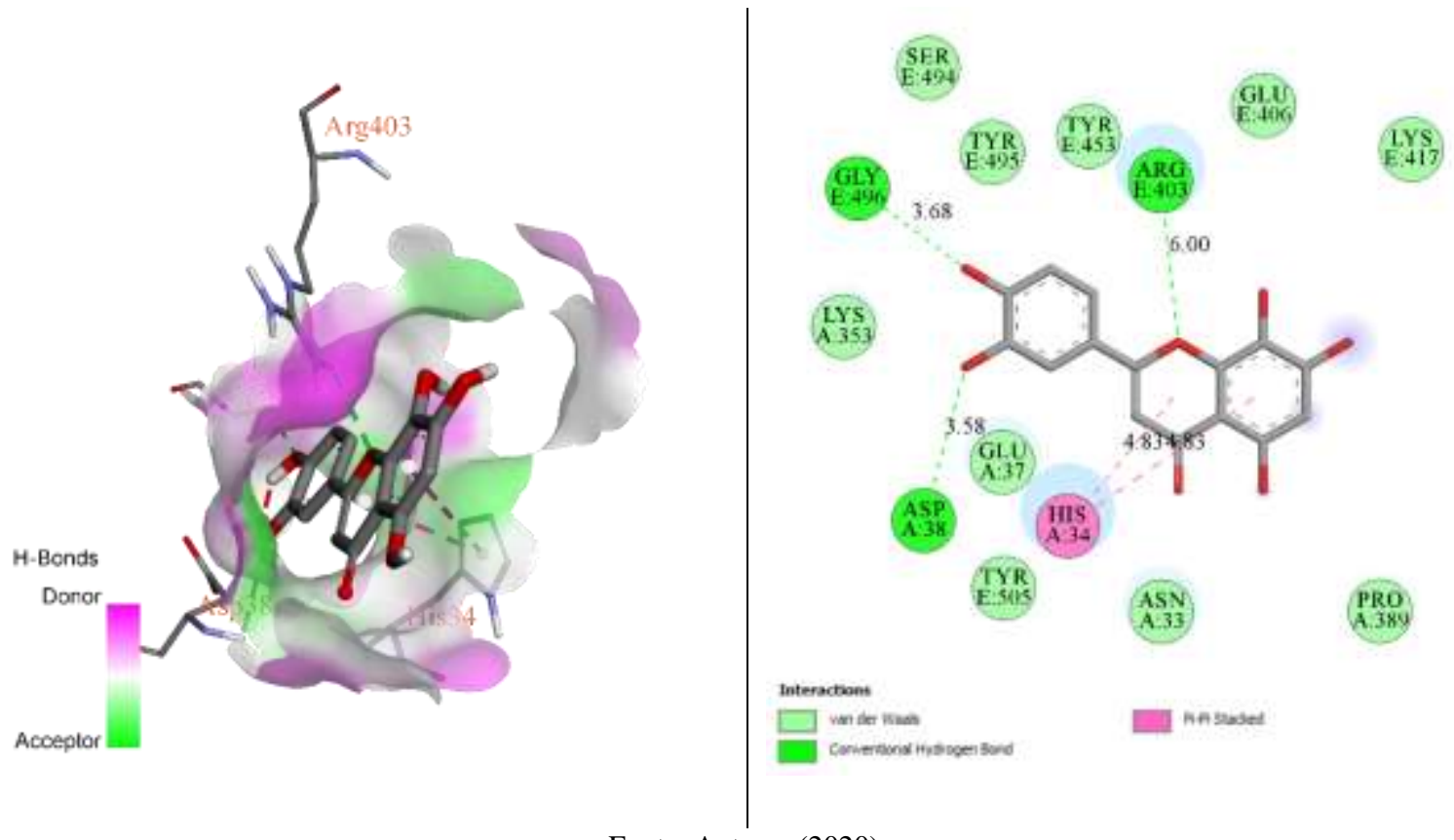

Fonte: Autores (2020).

O flavonoide Malvidina, Figura 21, realiza interações com três dos principais aminoácidos do RBD, sendo a Tyr 453 e Tyr 505 por meio de ligações de van der Waals, e com a Gly496 por meio de ligação de hidrogênio. Na ECA2, a interação ocorre com apenas um aminoácido chave, a Lys353, por ligação de van der Waals. 


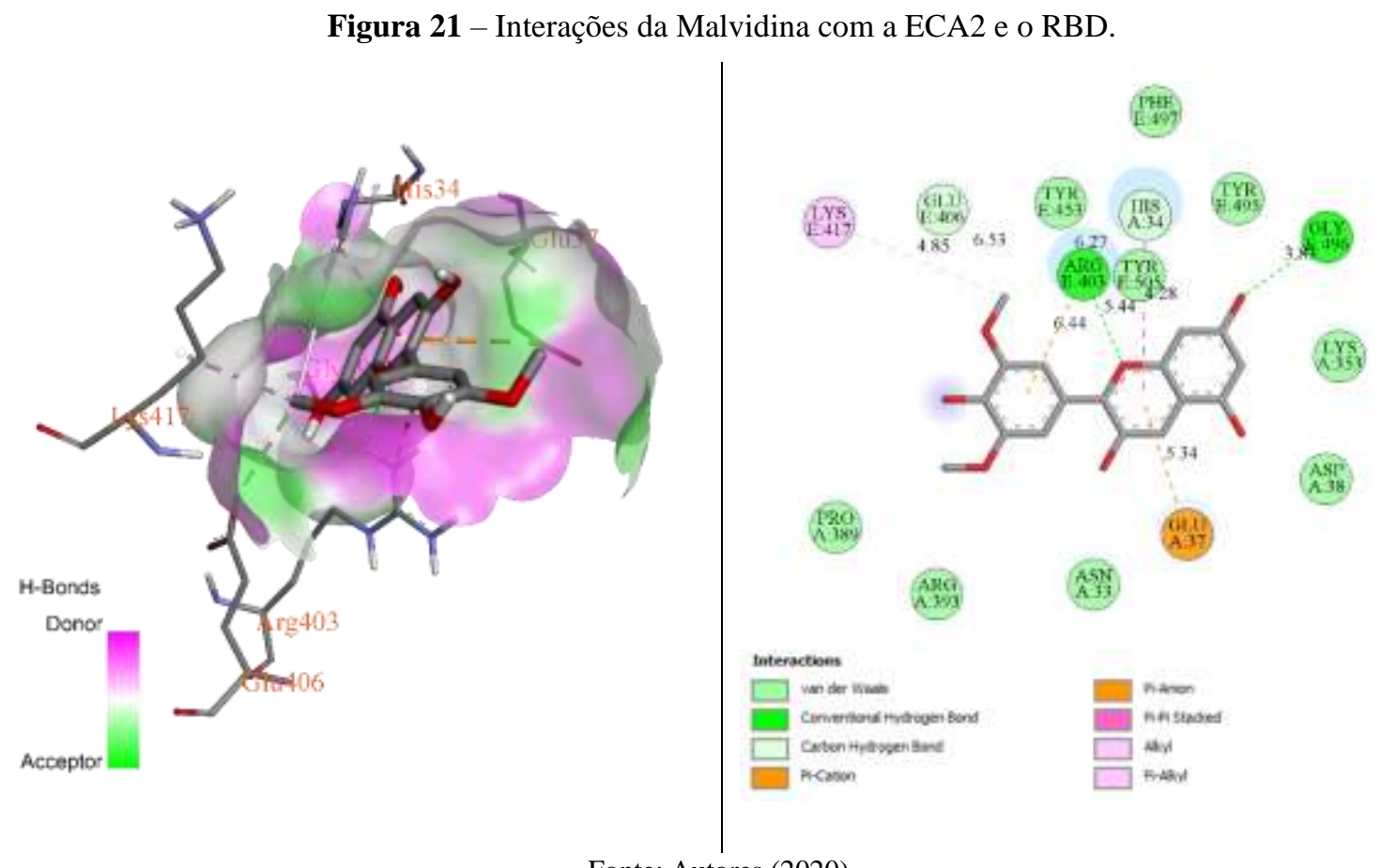

Fonte: Autores (2020).

O complexo formado entre a Salvigenina com a ECA2 + RBD (Figura 22), revela interações de van der Waals com três dos oito aminoácidos de maior relevância na formação do complexo proteico, sendo a Tyr453, Gly496 e Tyr505, sendo estes pertencentes ao RBD. Com a ECA2, o flavonoide interage apenas com a Lys353, por meio de ligação de hidrogênio.

Figura 22 - Interações da Salvigenina com a ECA2 e o RBD.

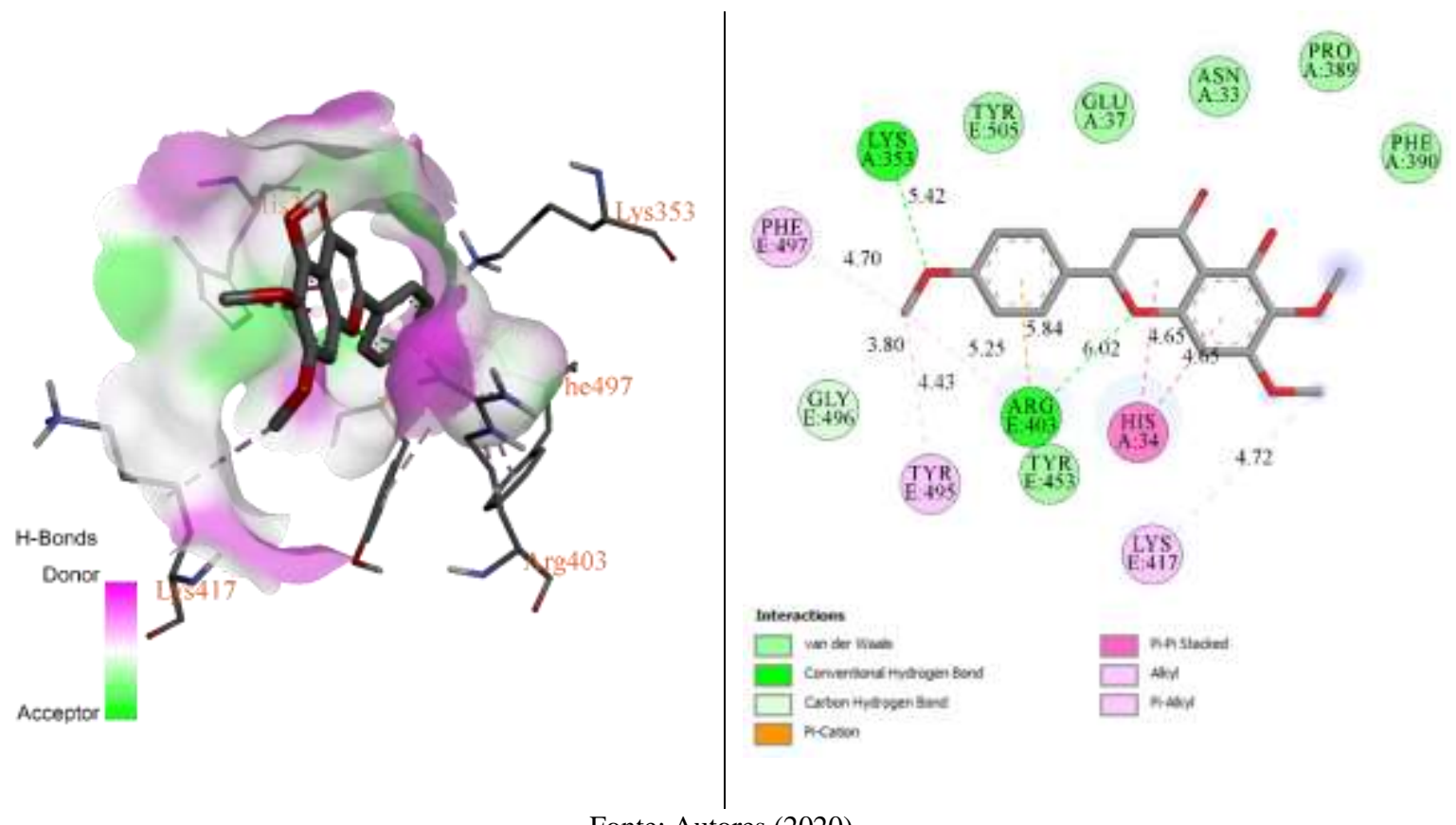

Fonte: Autores (2020).

No complexo entre o Xantomicrol com a ECA2 + RBD (Figura 23), observa-se que as interações ocorridas com os aminoácidos-chave do RBD e da ECA foram todas do tipo van der Waals. Com o RBD, o flavonoide interagiu com os resíduos Tyr453, Gly496 e Tyr505. Na ECA2, a interação foi apenas com a Lys353. 
Figura 23 - Interações do Xantomicrol com a ECA2 e o RBD.

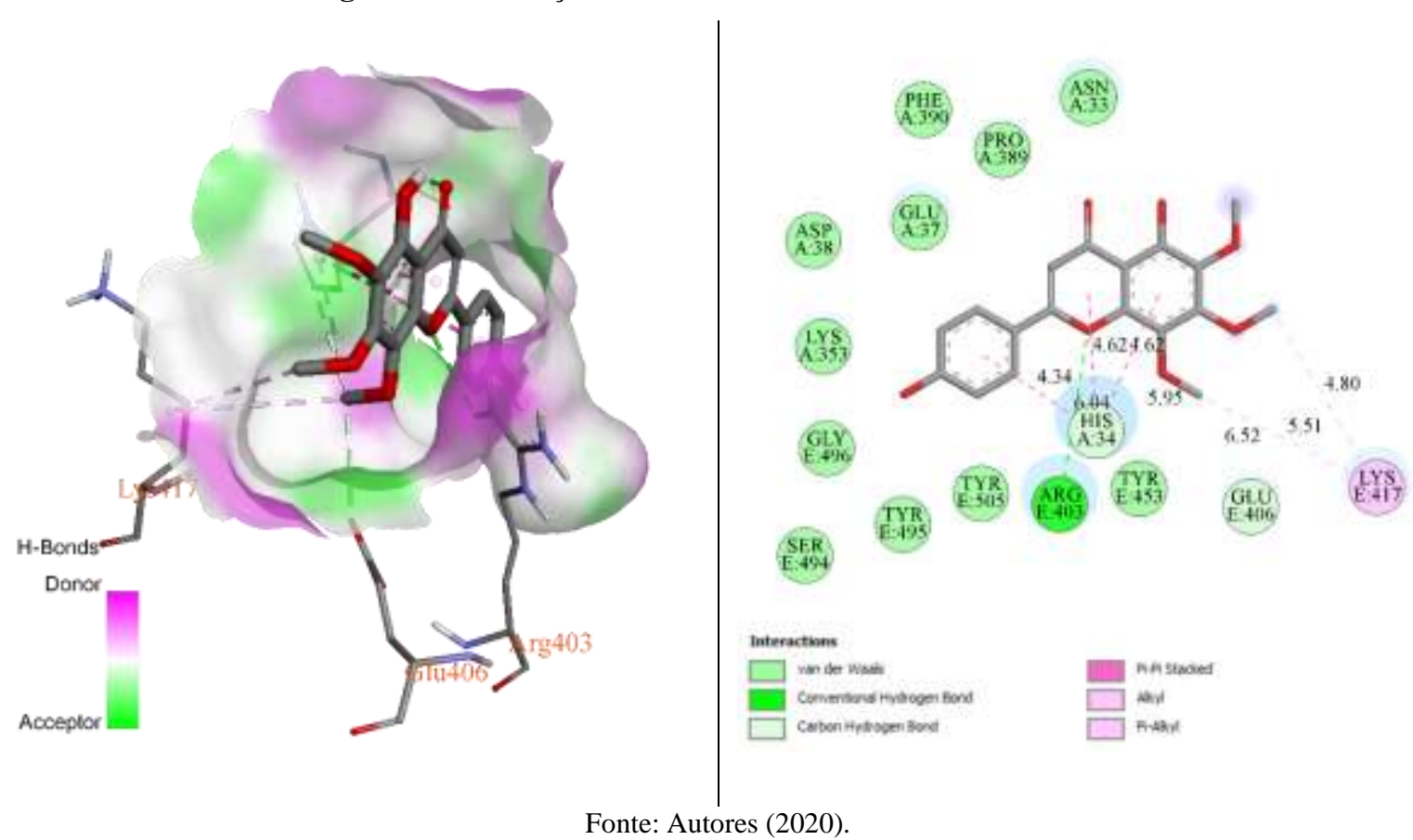

Fonte: Autores (2020).

Em um consenso entre as interações observadas, nota-se que todos os flavonoides realizaram interações com os aminoácidos Tyr453, Gly496 e Tyr505, pertencentes ao RBD. Na ECA2, todos fizeram interações com a Lys353. Tais aminoácidos demonstram-se in silico como de grande relevância para a interação dos flavonoides com o complexo proteico, não havendo interações desfavoráveis entre eles.

\section{Conclusão}

Os experimentos demonstraram que todos os flavonoides possuem capacidade teórica de interação com as proteínaschave do SARS-CoV-2, sendo mais favoráveis com o complexo entre a ECA2 + RBD. No complexo com a ProM, os flavonoides Escutelarina, Malvidina e Xantomicrol apresentaram as melhores interações com aminoácidos-chave da proteína, bem como possuíram afinidade de ligação considerável. Delfinidina, Hipoaletina e Salvigenina, embora tenham demonstrado altos valores de afinidade, possuem ligações não favoráveis para com a ProM.

O acoplamento dos flavonoides com a ECA2 + RBD aponta que, com exceção da Delfinidina, todos os demais compostos realizam interações favoráveis com o complexo proteico. A Delfinidina, ainda que possua um alto valor de afinidade no acoplamento, apresenta uma interação não favorável. A Hipoaletina destaca-se por possuir o maior valor de afinidade de ligação.

No contexto da Regra de Lipinski, apenas a Delfinidina apresentou duas violações, enquanto os demais flavonoides causaram apenas uma violação, indicativo de que a Escutelarina, Hipoaletina, Malvidina, Salvigenina e Xantomicrol são candidatos promissores a novos fármacos. A Delfinidina, por não se enquadrar na regra, não se mostra promissora, entretanto, $o$ uso de nanocarreadores poderia constituir-se como uma alternativa, para contornar a baixa biodisponibilidade da molécula.

Estudos posteriores envolvendo modelos in vitro e in vivo são necessários, a fim de se obter um maior entendimento a respeito do mecanismo de ação desempenhado pelos flavonoides da Lavanda, bem como comprovar seu efeito inibitório das proteínas-chave presentes na estrutura do SARS-CoV-2. 


\section{Referências}

Ali, A., \& Vijayan, R. (2020). Dynamics of the ACE2-SARS-CoV-2/SARS-CoV spike protein interface reveal unique mechanisms. Scientific Reports, 10(1). https://doi.org/10.1038/s41598-020-71188-3

Almeida, D. F. L. dos S. (2017). Estudo das vias metabólicas das plantas na síntese de pigmentos naturais. [Master's tesis] https://bdigital.ufp.pt/handle/10284/6104

Decaro, N., \& Lorusso, A. (2020). Novel human coronavirus (SARS-CoV-2): A lesson from animal coronaviruses. Veterinary microbiology, 244 , 108693. https://doi.org/10.1016/j.vetmic.2020.108693

Ferreira, A. R. A. (2014). Uso de óleos essenciais como agentes terapêuticos. [Master's tesis] https://bdigital.ufp.pt/handle/10284/4513

Frecer, V., \& Miertus, S. (2020). Antiviral agents against COVID-19: structure-based design of specific peptidomimetic inhibitors of SARS-CoV-2 main protease. RSC Advances, 10(66), 40244-40263. https://doi.org/10.1039/d0ra08304f

Gerhardt, T. E., \& Silveira, D. T. (2009). Métodos de Pesquisa. Editora da UFRGS. http://hdl.handle.net/10183/52806

Gobbo-Neto, L., \& Lopes, N. P. (2007). Plantas medicinais: fatores de influência no conteúdo de metabólitos secundários. Química Nova, 30(2), 374-381. https://doi.org/10.1590/s0100-40422007000200026

Gomes, J. N. S. (2019). Estudo in silico de derivados acrinídicos com potencial atividade antitumoral. Trabalho de Conclusão de Curso, Universidade Estadual da Paraíba, Campina Grande, Brasil.

Hamid, A. A., Aiyelaagbe, O. O., Usman, L. A. Essential oils: its medicinal and pharmacological uses. International Journal of Current Research, 3(2), 86-98. http://www.journalcra.com/sites/default/files/issue-pdf/406.pdf

Junior, V. F. V., Pinto, A. C., \& Maciel, M. A. M. (2005, June). Plantas medicinais: cura segura? Química Nova, 28(3), 519-528. https://doi.org/10.1590/S010040422005000300026

Lis-Balchin, M. (2002). Lavender: The Genus Lavandula (Medicinal and Aromatic Plants - Industrial Profiles). (1st ed.). CRC Press.

Machado, B. F. M. T., \& Junior, A. F. (2011). Óleos Essenciais: Aspectos Gerais E Usos Em Terapias Naturais. Cadernos Acadêmicos, 3(2), 105-127. http://www.portaldeperiodicos.unisul.br/index.php/Cadernos_Academicos/article/view/718

Malik Y. A. (2020). Properties of Coronavirus and SARS-CoV-2. The Malaysian journal of pathology, 42(1), 3-11.

Mirza, M. U., \& Froeyen, M. (2020). Structural elucidation of SARS-CoV-2 vital proteins: Computational methods reveal potential drug candidates against main protease, Nsp12 polymerase and Nsp13 helicase. Journal of Pharmaceutical Analysis, 10(4), 320-328. https://doi.org/10.1016/j.jpha.2020.04.008

Probst, I. S. (2014). Atividade antibacteriana de óleos essenciais e avaliação de potencial sinergético. [Master's tesis]. https://repositorio.unesp.br/handle/11449/87926?show=full

Salum, L. B. (2007). Estudos in silico no planejamento de candidatos a novos fármacos na terapia do câncer de mama e de reposição hormonal. [Master's tesis]. https://www.teses.usp.br/teses/disponiveis/76/76132/tde-09042008-121318/pt-br.php

Santos, A. L. P., Lima, G. W. R., \& Moraes, C. A. P. (2019). Estudo do potencial do óleo essencial de Lavandula angustiofolia L. como antimicrobiano. InterfacEHS - Saúde, Meio Ambiente e Sustentabilidade, 14(1), 63-72. http://www3.sp.senac.br/hotsites/blogs/InterfacEHS/wpcontent/uploads/2019/07/221_InterfaEHS_Artigo-63-72.pdf

Silva, G. L. F. (2016). KNECHTEL, Maria do Rosário. Metodologia da pesquisa em educação: uma abordagem teórico-prática dialogada. Curitiba: Intersaberes, 2014 (Resenha). Praxis Educativa, 11(2), 531-534. https://doi.org/10.5212/praxeduc.v.11i2.0013

Silva, S. M. (2015). Sistemas agrícolas e adubação na biomassa e óleo essencial de lavanda (Lavandula dentata L.) [Doctoral dissertation]. Universidade Federal de Uberlândia. https://repositorio.ufu.br/handle/123456789/12080

Sousa, F. C. F., Melo, C. T. V., Citó, M. C. O., Félix, F. H. C., Vasconcelos, S. M. M., Fonteles, M. M. F., Barbosa Filho, J. M., \& Viana, G. S. B. (2008). Plantas medicinais e seus constituintes bioativos: uma revisão da bioatividade e potenciais benefícios nos distúrbios da ansiedade em modelos animais. Revista Brasileira de Farmacognosia, 18(4), 642-654. https://doi.org/10.1590/s0102-695x2008000400023

Thomford, N. E., Senthebane, D. A., Rowe, A., Munro, D., Seele, P., Maroyi, A., \& Dzobo, K. (2018). Natural Products for Drug Discovery in the 21st Century: Innovations for Novel Drug Discovery. International journal of molecular sciences, 19(6), 1578. https://doi.org/10.3390/ijms19061578

Viegas Jr, C., Bolzani, V. D. S., \& Barreiro, E. J. (2006). Os produtos naturais e a química medicinal moderna. Química Nova, $29(2)$, 326-337. https://doi.org/10.1590/s0100-40422006000200025

Xavier, A. L. (2012). Design Teórico, Síntese Multicomponente e Comprovação Experimental da Atividade Antinociceptiva de Pirimidinonas em Camundongos através das vias Intraperitoneal e Oral. [Master's tesis]. https://repositorio.ufpe.br/handle/123456789/11945

Yuki, K., Fujiogi, M., \& Koutsogiannaki, S. (2020). COVID-19 pathophysiology: A review. Clinical immunology (Orlando, Fla.), 215 , 108427. https://doi.org/10.1016/j.clim.2020.108427 